\title{
A Fluxgate-based Current Sensor for DC Bias Elimination in a Dual Active Bridge Converter
}

\author{
Guanqun Qiu, Student Member, IEEE, Li Ran, Senior Member, IEEE, Hao Feng, Member, IEEE, Huaping Jiang, \\ Teng Long, Member, IEEE, Andrew Forsyth, Senior Member, IEEE, WeiHua Shao, Xu Hou
}

\begin{abstract}
A concern with the isolation transformer in a dual active bridge (DAB) DC-DC converter is the DC bias in magnetization. This paper proposes a fluxgate-based current sensor to measure the DC component mixed with a large, high-frequency AC current. Compared with a commercial Hall effect current sensor, the proposed sensor significantly reduces measurement error. This paper presents the working principle and design considerations. A prototype is demonstrated for DC bias elimination control in a DAB converter.
\end{abstract}

Index Terms - Transformer core saturation, DC bias, current sensor, fluxgate, current transformer, dual active bridge (DAB) DC-DC converter.

\section{INTRODUCTION}

Dual active bridge (DAB) DC-DC converters, as shown in Fig. 1, is becoming a popular topology in applications such as DC microgrids and distribution networks [1], battery storage systems [2], on-board EV chargers [3], and power electronic transformers [4], due to bidirectional power capability, high power density, electrical isolation, and zerovoltage-switching (ZVS) [5].



Fig. 1 Schematic of a DAB

A concern in operation is that the isolation transformer may be easily subject to DC bias [6]-[10] because of:

(1) different 'on' and 'off' times from the controller,

(2) inconsistent gating signal delays for deadband,

(3) asymmetry in PCB layout, and

(4) tolerance of device characteristics.

Guanqun Qiu, Hao Feng and Huaping Jiang is with the State Key Laboratory of Power Transmission Equipment and System Safety and New Technology, Chongqing University, Chongqing, 400044, China (e-mail: stefan.jiang@foxmail.com). Huaping Jiang is corresponding author

Li Ran is with the State Key Laboratory of Power Transmission Equipment and System Security and New Technology, Chongqing University, Chongqing 400044, China, and also with the School of Engineering, University of Warwick, Coventry CV4 7AL, U.K. (e-mail: 1.ran@warwick.ac.uk).

Teng Long is with Department of Engineering, University of Cambridge, Cambridge, CB2 1PZ, UK.

Andrew Forsyth is with Department of Electric and Electronic Engineering, University of Manchester, Manchester, M13 9PL, UK.

WeiHua Shao is with Industrial center/School of innovation and entrepreneurship Nanjing Institute of Technology Nanjing, Jiangsu, China.

$\mathrm{Xu}$ Hou is with State Grid Ningbo Zhenhai Power Supply Company, Zhejiang, China.
A DC voltage can quickly drive the transformer core into saturation, resulting in biased magnetizing current and extra core/winding losses. Two approaches are often considered. A series capacitor may be included with each winding [11]-[13], but this is inappropriate for high power applications owing to increased converter loss and volume, and sluggish dynamic response [14].

In the second approach, it is attempted to measure the DC bias and eliminate it in closed-loop control. But for the reasons that unfold below, accurate sensing of the DC current is a major challenge [15].

$\mathrm{DC}$ bias on the core of the DAB isolation transformer can come from either side, and it can be represented by the DC current component of the magnetizing current, viewed from the secondary side, this is

$$
I_{\mathrm{m}, \mathrm{DC}}=n I_{\mathrm{p}, \mathrm{DC}}-I_{\mathrm{s}, \mathrm{DC}}
$$

where $n$ is the turns ratio, $I_{\mathrm{p}, \mathrm{DC}}$ and $I_{\mathrm{s}, \mathrm{DC}}$ are the DC current components on primary and secondary sides, respectively. And $I_{\mathrm{m}, \mathrm{DC}}$ is DC component in magnetizing current.

Four control strategies are being pursued to eliminate DC bias, and they all depend on measurement:

(1) $n I_{\mathrm{p}, \mathrm{DC}}=I_{\mathrm{s}, \mathrm{DC}}$ for $I_{\mathrm{m}, \mathrm{DC}}=0$. It is possible that the winding currents contain DC components whose MMFs cancel in the core. In [16]-[22], the DC component of magnetizing current was eliminated by controlling the primary side duty cycle. However, the iron-cored inductor $L$ on this side for power transfer control may still suffer from saturation and cause the control to be unstable. Besides, the DC components in the winding currents increase the loss. A better way is to make the DC components in both winding currents to be zero, i.e. following methods (2) and (4).

(2) $I_{\mathrm{p}, \mathrm{DC}}=0$ and $I_{\mathrm{s}, \mathrm{DC}}=0$ for $I_{\mathrm{m}, \mathrm{DC}}=0$. In [23]-[26], the winding DC current components are separately sensed and then nulled simultaneously by control. Results are limited by the sensor accuracy. The absolute error of measurement increases with the range. Take the DAB in this study as an example. If sensor ranges on the two sides (ratio: 2:1) are 7.5 $\mathrm{A}$ and $15 \mathrm{~A}$ respectively and the relative error is typically $\pm 0.5 \%$, maximum absolute errors are then $37.5 \mathrm{~mA}$ and 75 $\mathrm{mA}$, resulting in a total error of $150 \mathrm{~mA}$ in $I_{\mathrm{m}, \mathrm{DC}}$, which is not trivial compared to the typical magnetizing current (e.g. 500 $\mathrm{mA}$ peak in this study).

(3) Direct DC flux control. Ref [27] proposes an extra winding to sense the saturation of an E-core with an air gap. In [28], a slot is carved into the core and a parallel magnetic core branch with a winding is added to the slot for sensing. In [29] and [30], the DC component of flux density is measured by a 'magnetic ear'. Refs [27]-[30] use different methods to detect the DC flux directly but only eliminate it by control from one of the windings. The disadvantage is the same as that in case (1). In [31], DC flux elimination using a tertiary winding is proposed. However, it is difficult to add a 
tertiary winding on some transformers. What is more, DC current can still be in the original windings.

(4) $I_{\mathrm{m}, \mathrm{DC}}=0$ and $I_{\mathrm{p}, \mathrm{DC}}=0$ for $I_{\mathrm{s}, \mathrm{DC}}=0$ or $I_{\mathrm{m}, \mathrm{DC}}=0$ and $I_{\mathrm{s}, \mathrm{DC}}=0$ for $I_{\mathrm{p}, \mathrm{DC}}=0$ [32]-[35]. Magnetizing current can be measured by running the DAB transformer winding leads through the same sensor in opposite directions for appropriate numbers of times. In comparison with case (2), because the measured 'magnetizing' current is much smaller than the winding load current, the sensor range could be reduced, which reduces the absolute measurement error. However, measuring in this way may be difficult as the sensor may have to accommodate many turns of the heavy-duty windings. As the method must also measure the DC component in one of the windings, it suffers from the same difficulty as case (2).

It is therefore desired to have a current sensor that can accurately measure a small DC component mixed in a large high-frequency $\mathrm{AC}$ current so that the control method can become more effective. Some state-of-the-art current sensors on the market, with range relevant to this study, are shown in TABLE I, without Rogowski coils and current transformers which are not for DC measurement.

TABLE I

SOME STATE-OF-THE-ART CURRENT SENSORS ON THE MARKET

\begin{tabular}{ccccc}
\hline \hline Category & Type & Range (A) & Accuracy & Error (mA) \\
\hline Shunt & $100 \mathrm{~m} \Omega$ & 15 & $1 \%$ & 150 \\
Hall & LAH 8 & 8 & $0.3 \%$ & 24 \\
Hall & LAH 12 & 12 & $0.3 \%$ & 36 \\
Hall & LAH 25 & 25 & $0.3 \%$ & 75 \\
Hall & LAH 50 & 50 & $0.25 \%$ & 125 \\
Hall & LAH 100 & 100 & $0.25 \%$ & 250 \\
GMR & AAV003 & 10 & $0.7 \%$ & 70 \\
Fluxgate & CKSR 15 & 15 & $0.8 \%$ & 120 \\
DC/AC & & & & \\
Fluxgate & GI-20s & 20 & $0.04 \%$ & 8 \\
DC & & 15 & $0.2 \%$ & 30 \\
OCT & COSI-CT & 50 & $0.2 \%$ & 100 \\
OCT & COSI-CT & 50 \\
OCT & COSI-CT & 100 & $0.2 \%$ & 200 \\
\hline
\end{tabular}

These are five types of current sensors: shunt, Hall effect, GMR (giant magnetoresistance), fluxgate and OCT (optical current transducer). The shunt, Hall, OCT and GMR types are currently not suitable for the intended application due to large errors. The accuracy of a DC fluxgate current sensor is sufficient, but it cannot be used to measure DC mixed in a large AC current, as shown later. To handle the $\mathrm{AC}$, the range of the current sensor needs to be relatively large. As the DC is small, using a sensor of a large range will increase the measurement error. Because there was no suitable current sensor, refs [27]-[31] proposed methods of measuring the transformer magnetic field directly to eliminate the DC bias.

The peak value of the magnetizing current in this study (DAB: $1 \mathrm{~kW}, 20 \mathrm{kHz}, n=2$ ) is about $500 \mathrm{~mA}$ and the AC current peaks are about 7.5 A and $15 \mathrm{~A}$, respectively. If $\mathrm{LAH}$ 25 and LAH 8 are used to measure the DC components in the winding currents, the maximum error of the magnetizing current (referred to the secondary side) obtained from the measurements is about $123 \mathrm{~mA}$ which is not negligible compared to $500 \mathrm{~mA}$.

In the DAB transformer design, it is common to have a margin in the core area. If the accuracy of DC measurement is higher, the bias can be reduced through control. The core design margin can then be reduced.

In summary, a key challenge is to accurately sense the DC component mixed in a large high-frequency AC current which defines the measurement range. This study proposes a low-cost scheme, making use of the fluxgate and current transformer principles. The key feature is that the AC influence is avoided so that the DC current measurement range and hence error are small.

The rest of the paper is organized as follows. Section II introduces the working principle and characteristics of the proposed sensor, while its parameter selection is presented in Section III. Section IV demonstrates the use of the prototype sensors to eliminate the DAB transformer DC bias. Section V concludes the paper.

\section{CONFIGURATION AND WORKING PRINCIPLE}

\section{A. Principle of single-core fluxgate current sensor}

A single-core fluxgate can accurately measure a pure DC current [36]. Its structure is shown in Fig. 2. $W_{0} \sim W_{2}$ are three separate windings on a toroidal core. $I_{\mathrm{DC}}$ denotes the measured DC current. $W_{1}$ is the magnetizing winding. $v_{1}(t)$ and $i_{1}(\mathrm{t})$ represent the input voltage and magnetizing current, which are generated from a triangle-wave generator. If needed, resistance $R_{1}$ can prevent the triangle-wave generator from being short-circuited as the core saturates. Induced winding voltage $v_{2}(t)$ becomes a $0-3.3 \mathrm{~V}$ square wave, $v_{2}{ }_{2}(t)$, after signal conditioning, as the fluxgate sensor output.

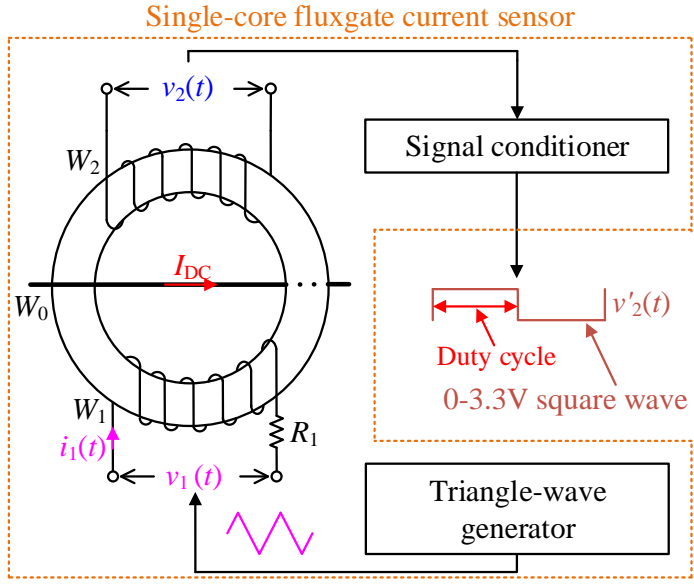

Fig. 2 A single-core fluxgate DC current sensor.

The working principle of a fluxgate is now explained. When the toroidal core is not saturated, the waveforms of $v_{1}(t), B_{1}(t)$ and $v_{2}(t)$ are shown in Fig. 3. Here, $B_{1}(t)$ is the core flux density. $B_{\mathrm{s}}$ is the saturation flux density, above $B_{1}(t)$. With the resistive voltage drop ignored in the circuit, $B_{1}(t)$ is roughly the integral of $v_{1}(t)$. As $v_{1}(t)$ is piece-wise linear, $B_{1}(t)$ is piece-wise quadratic with a linear part (red) and a nonlinear part (green), as shown. $B_{1}(t)$ is not an ideal triangle-wave, it is top flattened corresponding to the zero-crossing of $v_{1}(t)$.

When the core saturates and $I_{\mathrm{DC}}=0$, the waveform of $v_{2}(t)$ is shown in Fig. 4. Since the rate of change of $B_{1}(t)$ in the saturated part is close to zero, the previous triangular waveform is reduced to a narrower shape. The solid line is the waveform after the core is saturated. When the saturation is symmetrical in both directions with $I_{\mathrm{DC}}=0$, the waveform of $v_{2}(t)$ remains half-wave symmetrical and the duty cycle of $v_{2}^{\prime}(t)$ is $50 \%$. 




Fig. 3 Waveforms of $v_{1}(t), B_{1}(t)$ and $v_{2}(t)$ when the core is not saturated.

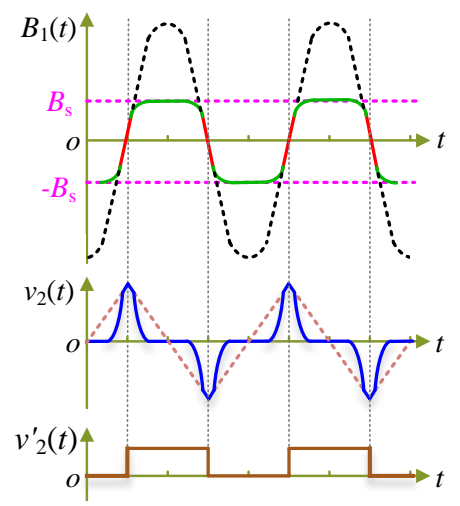

Fig. 4 Waveforms when the core is saturated and $I_{\mathrm{DC}}=0$.

When $I_{\mathrm{DC}} \neq 0$, it produces a DC flux density $B_{\mathrm{DC}}$ that is superimposed to $B_{1}(t)$, which shifts $B_{1}(t)$ up or down, as shown in Fig. 5.

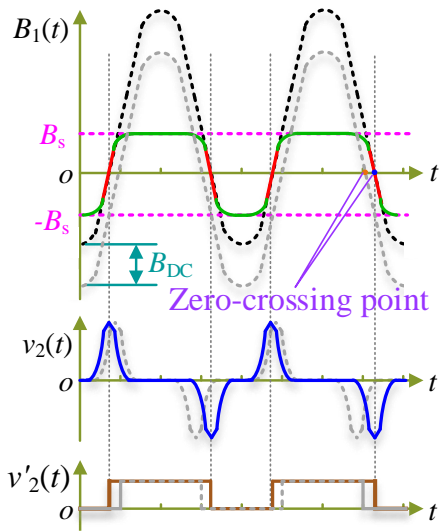

Fig. 5 Waveforms of $B_{1}(t), v_{2}(t)$ and $v_{2}^{\prime}(t)$ when the core is saturated and $I_{\mathrm{DC}} \neq 0$.

Correspondingly, the distance between consecutive zero-crossings of the $v_{2}(t)$ waveform changes. This causes the duty cycle of $v_{2}^{\prime}(t)$ to change. As long as the zero-crossing point remains in the linear region of $B_{1}(t)$, the duty cycle of $v_{2}{ }_{2}(t)$ changes proportionally to the measured DC current. The duty cycle cannot be changed from 50\% to $100 \%$, because the pulses of $v_{2}(t)$ have a certain width. The intervals during which $v_{2}(t)$ is zero will determine the utilization range of the duty cycle. This will be considered in the sensor design Fig. 6 shows the measured waveforms of $v_{2}(t)$, which are similar to those derived above.

According to Fig. 4, Fig. 5 and Fig. 6, the principle of the fluxgate is to use a saturable no-load transformer to detect the DC magnetic field. The key to achieving the fluxgate function is whether the core can be saturated. In a no-load transformer, the criterion for judging whether the core is saturated is [37]:

$$
\left\{\begin{array}{l}
B_{1 \mathrm{p}} \geq B_{\mathrm{s}} \\
B_{1 \mathrm{p}}=v_{\mathrm{lp}} / m N_{1} A_{\mathrm{c}} f_{1}
\end{array}\right.
$$

where $v_{1 \mathrm{p}}$ and $B_{1 \mathrm{p}}$ are the peak values of $v_{1}(t)$ and $B_{1}(t)$, respectively. $A_{\mathrm{c}}$ is cross-sectional area of the sensor core, $N_{1}$ the number of turns of $W_{1}$, and $f_{1}$ the frequency of $v_{1}(t)$. $m$ is the waveform coefficient. When $v_{1}(t)$ is triangle wave, $m=4$.



(a)



(b)
Fig. 6 Real waveforms of $v_{2}(t)$. (a) when $I_{\mathrm{DC}}=0$. (b) $v_{2}(t)$ when $I_{\mathrm{DC}} \neq 0$.

The range of the fluxgate sensor is determined by the difference between $B_{1 \mathrm{p}}$ and $B_{\mathrm{s}}$. This is because $B_{1 \mathrm{p}}-B_{\mathrm{s}}$ is to ensure that DC flux density produced by the measured DC current within the set range will not make the core exit saturation (i.e. $-B_{1 \mathrm{p}}+B_{\mathrm{DC}}>-B_{\mathrm{s}}$ or $B_{1 \mathrm{p}}-B_{\mathrm{DC}}<B_{\mathrm{s}}$ will not happen). The range can be expressed as

$$
\left\{\begin{array}{l}
I_{\mathrm{r}, \mathrm{DC}}=\left(B_{1 \mathrm{p}}-B_{\mathrm{s}}\right) l_{c} /\left(\mu_{0} \mu_{r} N_{0}\right) \\
B_{1 \mathrm{p}}=v_{1 \mathrm{p}} / m N_{1} A_{\mathrm{c}} f_{1}
\end{array}\right.
$$

where $I_{\mathrm{r}, \mathrm{DC}}$ is the set range, $\mu_{0}$ is the vacuum permeability, $\mu_{\mathrm{r}}$ relative permeability of the core, $N_{0}$ the number of turns of $W_{0}$, and $l_{\mathrm{c}}$ the core length.

Because the $v_{1 \mathrm{p}}$ can also determine the saturation degree of the core, the range of fluxgate is realized by adjusting $v_{1 p}$. When $v_{\mathrm{p}}$ is met, if the triangle-wave generator can provide enough magnetizing current $i_{1}(t)$, the core will be saturated and can meet the set range.

\section{B. Restriction of fluxgate and a solution}

The single-core fluxgate sensor can measure a pure DC current accurately. However, as shown in Fig. 7(a), when it is used to measure the DC component in a DAB transformer winding current, the AC part of the current $i_{\mathrm{ho}}(t)$ will induce voltages $v_{\mathrm{h} 1}(t)$ and $v_{\mathrm{h} 2}(t)$ on $W_{1}$ and $W_{2}$, respectively.

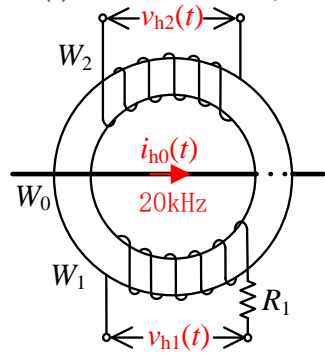

(a)

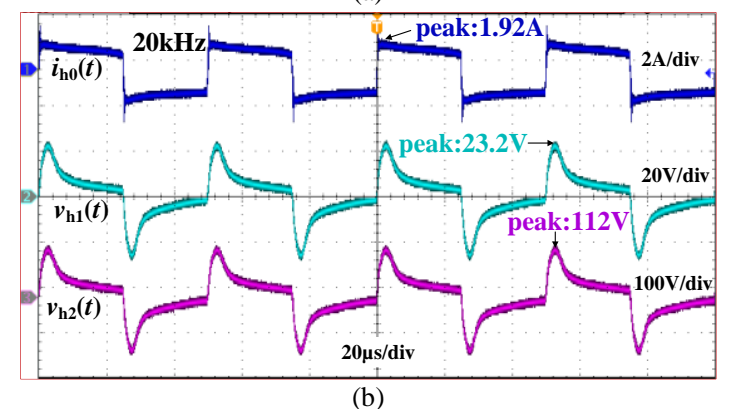

Fig. 7 Impact of DAB winding current on fluxgate, with $N_{1}=87$ and $N_{2}=$ 397 (numbers of turns of $W_{1}$ and $W_{2}$ ). (a) experiment arrangement; (b) experiment result when a $\mathrm{DAB}$ winding current flows through $W_{0}$. 
In Fig. 2, both $W_{1}$ and $W_{2}$ are connected to high impedance circuitry. Therefore the peak values of $v_{\mathrm{h} 1}(t)$ and $v_{\mathrm{h} 2}(t)$ can both be high, as shown in Fig. 7(b). Depending on the number of turns and the DAB switching frequency, these voltages are usually large enough to destroy the op-amps of the signal conditioner and triangle-wave generator. This is the reason why the single-core fluxgate current sensor can not be used for the intended application.

To reduce $v_{\mathrm{h} 1}(t)$ and $v_{\mathrm{h} 2}(t)$, the output impedance of the sensor transformer must be reduced. Therefore, a relatively small resistor $R_{2}$ (to be selected as $120 \Omega$ in this study) is connected across $W_{2}$, as shown in Fig. 8. The peak values decrease significantly, as shown in Fig. 9.

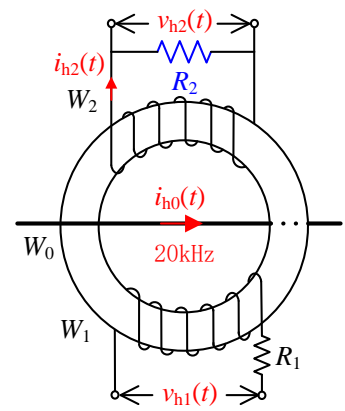

Fig. 8 Schematic diagram with a resistor connected across $W_{2}$



Fig. 9 High-frequency voltage in fluxgate windings when $W_{2}$ is connected to a $120 \Omega$ resistor and the DAB is fully loaded with $i_{\mathrm{h} 0}(t)$ of $15 \mathrm{~A}$ peak.

\section{Negative impact of the proposed method on fluxgate}

The experiment results in Fig. 9 show that the proposed method is effective. However, the negative impact of $R_{2}$ on fluxgate must be analyzed and the related circuit redesigned if needed. Three different flux densities are superimposed in the core: DC, the 'triangle-wave' (i.e. that associated with $\left.v_{1}(t)\right)$ and high-frequency flux densities. To simplify the analysis, these three flux densities are considered separately, and then combined to form a complete model.

\section{(1) Impact of high-frequency current}

Fig. 10 shows an equivalent circuit of Fig. 8 [37]-[38], which is used to analyze the impact of the high-frequency flux density.



Fig. 10 High-frequency equivalent circuit.
Here, $L_{\mathrm{k} 0}, L_{\mathrm{k} 1}$ and $L_{\mathrm{k} 2}$ are the winding leakage inductances. $L_{\mathrm{m} 0}$ is the magnetizing inductance from $W_{0} . N_{0}, N_{1}$ and $N_{2}$ are the numbers of turns of $W_{0}, W_{1}$ and $W_{2}$, respectively. $i_{\mathrm{h} 0}(t)$ is the excitation current source. $i_{\mathrm{h} 2}(t)$ is the high-frequency current in $W_{2} . i_{\mathrm{m} 0}(t)$ is a high-frequency magnetizing current producing $B_{0}(t)$. $v_{\mathrm{h} 1}(t)$ and $v_{\mathrm{h} 2}(t)$ are produced by $B_{0}(t)$.

According to KVL, Faraday's law and the transformer principle, the relationship between these variables on the three windings is

$$
\left\{\begin{array}{l}
v_{\mathrm{h} 2}(t)=N_{2} A_{\mathrm{c}} \frac{d B_{0}(t)}{d t}-L_{k 2} \frac{d i_{\mathrm{h} 2}(t)}{\mathrm{dt}} \\
v_{\mathrm{h} 2}(t)=i_{\mathrm{h} 2}(t) R_{2} \\
i_{\mathrm{h} 2}(t)=i_{\mathrm{h} 0}(t) N_{0} / N_{2} \\
v_{\mathrm{h} 1}(t)=N_{1} A_{\mathrm{c}} \frac{d B_{0}(t)}{d t} \\
B_{0}(t)=\mu_{0} \mu_{\mathrm{r}} N_{0} i_{\mathrm{m} 0}(t) / l_{\mathrm{c}}
\end{array}\right.
$$

According to (4), the leakage inductance accounts for part of $v_{\mathrm{h} 2}(t)$. Due to $L_{\mathrm{k} 2}$ being very small compared to the self-inductance of $W_{2}$, it has little effect on the fluxgate.

The key to the realization of a fluxgate is core saturation. Therefore, whether the peak value of $B_{0}(t)$ will affect core saturation should be analyzed. The relationship between the peak value of $B_{0}(t)$ and $v_{\mathrm{h} 2}(t)$ satisfies [37]:

$$
v_{\mathrm{h} 2 \mathrm{p}}=4 N_{2} A_{\mathrm{c}} f_{\mathrm{s}} B_{0 \mathrm{p}}
$$

where $v_{\mathrm{h} 2 \mathrm{p}}$ and $B_{0 \mathrm{p}}$ are the peak values of $v_{\mathrm{h} 2}(t)$ and $B_{0}(t)$, respectively. $f_{\mathrm{s}}$ is the switching frequency of the $\mathrm{DAB}$, i.e. $20 \mathrm{kHz}$. The influence of $L_{\mathrm{k} 2}$ has been ignored in (5).

In the study case, $v_{\mathrm{h} 2 \mathrm{p}}$ is obtained from Fig. 9 and is about $2.4 \mathrm{~V}$ when the DAB is fully loaded. Substituting $v_{\mathrm{h} 2 \mathrm{p}}=2.4 \mathrm{~V}$ into (5) gives $B_{0 \mathrm{p}} \approx 0.00035 \mathrm{~T}$. Due to $N_{2}$ being large in this study, $B_{0 \mathrm{p}}$ is small. The saturation flux density of the selected core is $0.7 \mathrm{~T}$, far greater than $0.00035 \mathrm{~T}$. Therefore, $B_{0}(t)$ has little impact on core saturation. In other words, $B_{0}(t)$ hardly affects the normal operation of the fluxgate.

\section{(2) Influence of $R_{2}$ on fluxgate}

Fig. 11 is the equivalent circuit used to analyze the influence of $R_{2}$ on the fluxgate.

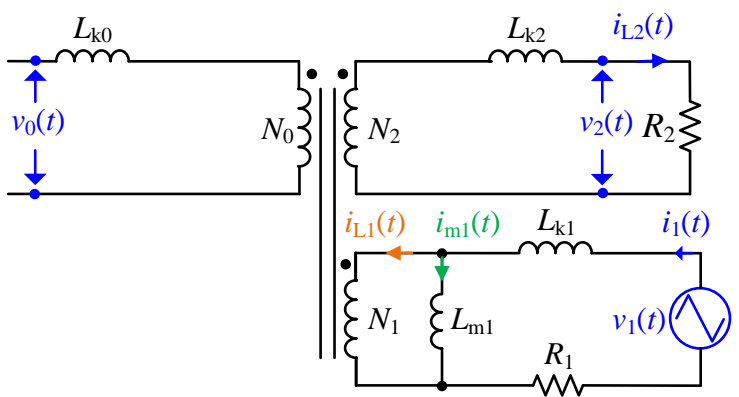

Fig. 11 Equivalent circuit of proposed sensor focusing on triangle-wave frequency component.

$L_{\mathrm{m} 1}$ is magnetizing inductance from $W_{1}$. When $R_{2}$ is added, $W_{1}, W_{2}$, the toroidal core and $R_{2}$ form a current transformer (CT). Therefore, $i_{1}(t)$ is the excitation current source. $i_{1}(t)$ is divided into the magnetizing current $i_{\mathrm{m} 1}(t)$ and load current $i_{\mathrm{L} 1}(t) . i_{\mathrm{m} 1}(t)$ produces $B_{1}(t) . v_{0}(t)$ and $v_{2}(t)$ are produced by $B_{1}(t) . i_{\mathrm{L} 2}(t)$ is the load current. According to KVL, Faraday's law and the transformer principle, the relationship between the three windings in Fig. 11 is 


$$
\left\{\begin{array}{l}
v_{0}(t)=N_{0} A_{\mathrm{c}} \frac{d B_{1}(t)}{d t} \\
v_{2}(t)=N_{2} A_{\mathrm{c}} \frac{d B_{1}(t)}{d t}-L_{k 2} \frac{d i_{\mathrm{L} 2}(t)}{d t} \\
v_{2}(t)=i_{\mathrm{L} 2}(t) R_{2} \\
i_{1}(t)=i_{\mathrm{L} 1}(t)+i_{\mathrm{m} 1}(t) \\
i_{\mathrm{L} 2}(t)=N_{1} i_{\mathrm{L} 1}(t) / N_{2} \\
B_{1}(t)=\mu_{0} \mu_{\mathrm{r}} N_{1} i_{\mathrm{m} 1}(t) / l_{\mathrm{c}}
\end{array}\right.
$$

To realize the fluxgate function, the CT $\left(W_{1}, W_{2}\right.$, the toroidal core and $R_{2}$ ) core still needs to be saturated. In the $\mathrm{CT}, W_{1}$ is regarded as a current source, hence, the peak value of $v_{2}(t)$, i.e. $v_{2 \mathrm{p}}$, determines core saturation and the sensor range. The relationship satisfies

$$
\left\{\begin{array}{l}
B_{1 \mathrm{p}} \geq B_{\mathrm{s}} \\
B_{1 \mathrm{p}}=v_{2 \mathrm{p}} / m N_{2} A_{\mathrm{c}} f_{1} \\
v_{2 \mathrm{p}}=i_{\mathrm{L} 2 \mathrm{p}} R_{2} \\
i_{\mathrm{L} 2 \mathrm{p}}=i_{\mathrm{L} 1 \mathrm{p}} N_{2} / N_{1}
\end{array}\right.
$$

where, $i_{\mathrm{L} 1 \mathrm{p}}$ and $i_{\mathrm{L} 2 \mathrm{p}}$ are the peak values of $i_{\mathrm{L} 1 \mathrm{p}}(t)$ and $i_{\mathrm{L} 2 \mathrm{p}}(t)$.

From (7), $B_{1 \mathrm{p}}$ is determined by $R_{2}$ and $i_{\mathrm{Llp}}$. therefore, adjusting $R_{2}$ and $i_{\mathrm{Llp}}$, the core can be saturated, which is used to parameter design in the next section.

\section{(3) Complete model of the proposed sensor}

The complete model of the proposed sensor is shown in Fig. 12, which combines the models shown in Fig. 10 and Fig. 11, and also includes $I_{\mathrm{DC}}$. Here, $v_{\mathrm{w} 0}(t), v_{\mathrm{w} 1}(t)$ and $v_{\mathrm{w} 2}(t)$ are the total voltages of $W_{0}, W_{1}, W_{2} . i_{\mathrm{w} 0}(t), i_{\mathrm{w} 1}(t)$ and $i_{\mathrm{w} 2}(t)$ are the total currents.



Fig. 12 A complete model of the proposed sensor.

It can be seen from Fig. 12 that $W_{0}, W_{1}$ and $W_{2}$ are coupled by flux density $B(t)$ in the core, which satisfies

$$
B(t)=B_{0}(t)+B_{1}(t)+B_{\mathrm{DC}}
$$

Correspondingly, the main components in the winding voltages and currents are

$$
\left\{\begin{array}{l}
v_{\mathrm{w} 0}(t)=v_{0}(t) \\
v_{\mathrm{w} 1}(t)=v_{1}(t)+v_{\mathrm{h} 1}(t) \\
v_{\mathrm{w} 2}(t)=v_{2}(t)+v_{\mathrm{h} 2}(t) \\
i_{\mathrm{w} 0}(t)=I_{\mathrm{DC}}+i_{\mathrm{h} 0}(t) \\
i_{\mathrm{w} 1}(t)=i_{1}(t) \\
i_{\mathrm{w} 2}(t)=i_{\mathrm{L} 2}(t)+i_{\mathrm{h} 2}(t)
\end{array}\right.
$$

When $N_{0}$ is 1 as in this study, $v_{\mathrm{w} 0}(t)=v_{0}(t) \approx 0$ provided that $N_{1}>>1$ $v_{\mathrm{w} 1}(t)$ contains $v_{\mathrm{h} 1}(t)$ and $v_{1}(t) . v_{\mathrm{h} 1}(t)$ is the interference voltage whose peak value must be less than the withstand voltage of op-amp to avoid damage to the op-amp, which is realized by the termination resistance as shown in Fig.9. $v_{\mathrm{w} 2}(t)$ contains $v_{\mathrm{h} 2}(t)$ and $v_{2}(t)$ where $v_{2}(t)$ is the desired output and $v_{\mathrm{h} 2}(t)$ is the interference that should be filtered out.

\section{(4) Redesigned signal conditioning circuit}

Based on the above analysis, the frequency of $v_{2}(t)$ (i.e. triangle-wave frequency) must be considerably lower than the frequency of $v_{\mathrm{h} 2}(t)$ (i.e. the DAB switching frequency), so that it is convenient to filter out $v_{\mathrm{h} 2}(t)$ by a low-pass filter. In line with this, the signal processing circuit of fluxgate has been redesigned, as shown in Fig. 13. There are two low-pass filters and a differential amplifier before the signal conditioner. A common-mode inductor is added on $W_{1}$. This is because winding parasitic capacitance can cause coupling with the DAB operation giving rise to common-mode interference that can seriously affect the signal conditioning circuit. This is particularly important in DAB units with high DC bus voltages.

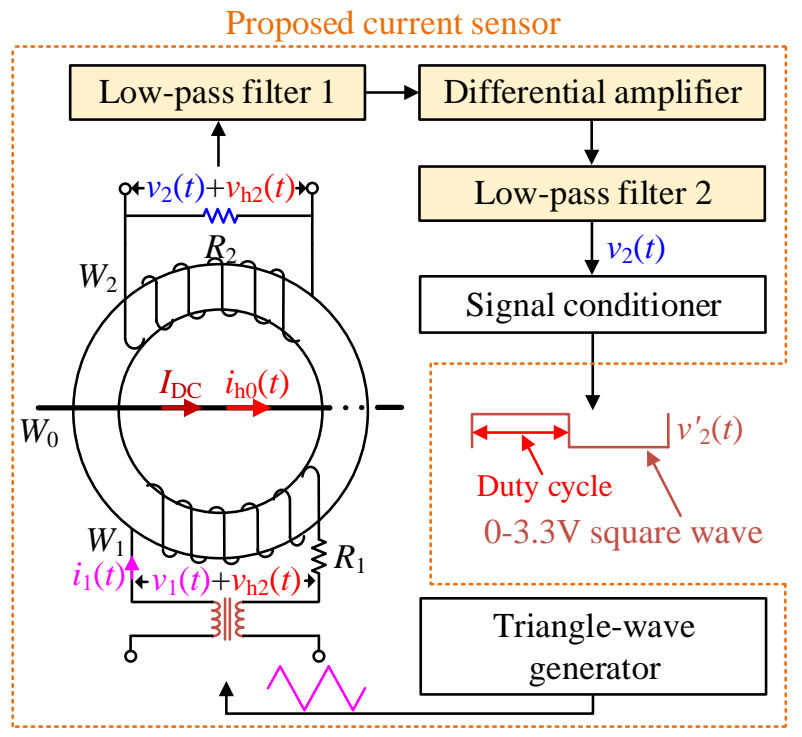

Fig. 13 Configuration of the proposed sensor.

\section{PARAMETER DESIGN OF SENSOR SYSTEM}

\section{A. Sensor requirements}

The working principle of the sensor means that it is unlikely to be a standard, off-the-shelf device. Instead, it should be designed to fit the DAB because it has to handle the high-frequency $\mathrm{AC}$ and at the same time provide the required range and resolution for DC current measurement. TABLE II shows the parameters of the experimental $1 \mathrm{~kW}$ DAB. As a design example, this paper will design a fluxgate sensor for this DAB.

To allow transient in control, the sensor range is set at three times of $I_{\mathrm{DC}}$ which is the DC component added in a DAB winding current that will just saturate the DAB transformer core. It can be calculated as

$$
\left\{\begin{array}{l}
B_{\mathrm{w}}=V_{\mathrm{pk}} /\left(4 N A_{\mathrm{m}} f_{\mathrm{s}}\right) \\
B_{\mathrm{DC}}=B_{\mathrm{s}, \mathrm{DAB}}-B_{\mathrm{w}} \\
I_{\mathrm{DC}}=B_{\mathrm{DC}} l_{\mathrm{m}} /\left(\mu_{0} \mu_{r} N\right)
\end{array}\right.
$$


where $B_{\mathrm{s}, \mathrm{DAB}}$ is the saturation flux density of DAB transformer core, $B_{\mathrm{w}}$ the working peak flux density, $V_{\mathrm{pk}}$ the amplitude of DAB winding voltage, $N$ the number of turns of corresponding winding, $A_{\mathrm{m}}$ the cross-sectional area of DAB transformer core, and $l_{\mathrm{m}}$ the core length.

TABLE II

PARAMETERS OF 1KW EXPERIMENTAL DAB

\begin{tabular}{lc}
\hline \multicolumn{1}{c}{ Parameter } & Value \\
\hline \hline Rated power & $1 \mathrm{~kW}$ \\
Primary winding rated voltage & $200 \mathrm{~V}$ \\
Secondary winding rated voltage & $100 \mathrm{~V}$ \\
Primary side rated DC current & $5 \mathrm{~A}$ \\
Secondary side rate DC current & $10 \mathrm{~A}$ \\
Peak value of primary winding rated current & $15 \mathrm{~A}$ \\
Peak value of secondary winding rated current & $7.5 \mathrm{~A}$ \\
Primary winding turns & 30 \\
Secondary winding turns & 15 \\
Auxiliary inductance & $120 \mu \mathrm{H}$ \\
Switching frequency & $20 \mathrm{kHz}$ \\
Core material & PC95 \\
Magnetic permeability (at $20 \mathrm{kHz})$ & 3300 \\
Saturation $B$ (at $60^{\circ} \mathrm{C}$ ) & $0.48 \mathrm{~T}$ \\
Magnet core length & $11.3 \mathrm{~cm}$ \\
Core effective cross-sectional area & $3.28 \mathrm{~cm}{ }^{2}$ \\
\hline
\end{tabular}

With the data in TABLE II, $I_{\mathrm{DC}}$ is about $0.2 \mathrm{~A}$ on the primary and $0.4 \mathrm{~A}$ on the secondary side. The sensor range is set at three times of 0.4 A, i.e. $\pm 1.2 \mathrm{~A}$.

The resolution of measurement should be as small as possible, e.g. $1 \mathrm{~mA}$ in this study. With this, the absolute error will be smaller than that of a Hall effect sensor.

\section{B. Design for resolution}

Factors that affect the resolution of fluxgate are: the relative permeability $\mu_{\mathrm{r}}$ of core, the triangle-wave frequency $f_{1}$ and its resolution, the DSP clock frequency and the range of the sensor.

A high relative permeability $\mu_{\mathrm{r}}$ of the sensor toroidal core leads to a high resolution. High permeability means a large flux density change by the same DC current, and hence a great change in the sensor's output in terms of duty cycle.

In this study, the DSP used to control the DAB is also used to measure the DC current, by counting its own pulses in the duty cycle of the sensor's output square wave, as shown in Fig. 14. Two observations are made here: if the resolution is higher for the triangle-wave or the DSP clock frequency, the resolution of the sensor out will be higher; if the triangle-wave frequency is lower or the target DC range is smaller, the resolution of the sensor output will also be higher, i.e. finer. Fig. 15 is the flow chart of the resolution design.

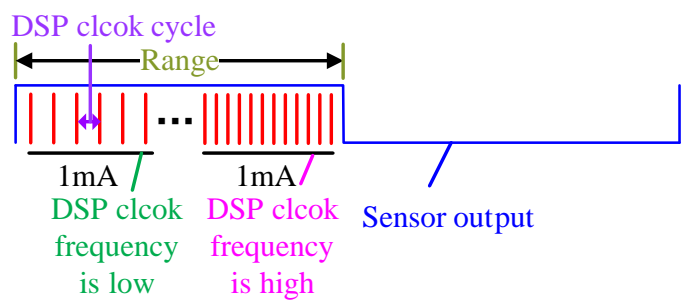

Fig. 14 Way for DSP to measure duty cycle, by counting clock pulses in the range of the signal conditioner output which represents DC current.

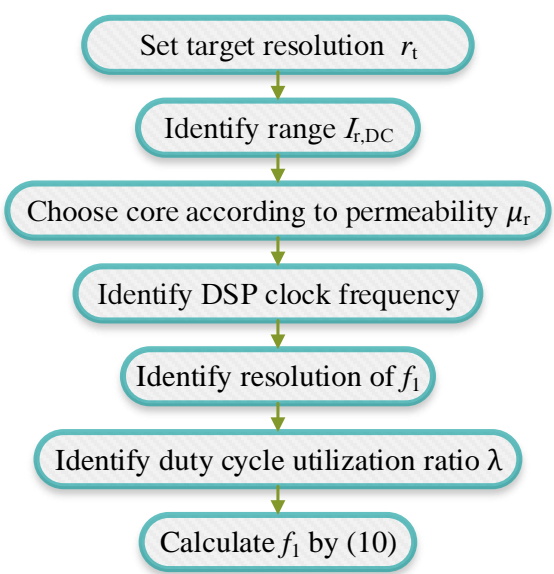

Fig. 15 Flow chart of resolution design. $\mu_{\mathrm{r}}$, the resolution of $f_{1}$ and the DSP clock frequency are selected from what is available. Only $f_{1}$ can be flexibly adjusted. The sensor resolution is designed through it.

Eqn. (11) is used to calculate $f_{1}$. The change of the duty cycle corresponding to the measurement resolution must be greater than that corresponding to the resolution of $f_{1}$ itself. With the duty cycle replaced by time, the relationship is

$$
\left\{\begin{array}{l}
T_{\mathrm{r}}=\lambda T_{1} \mathrm{r}_{t} / I_{\mathrm{r}, \mathrm{DC}}=\mathrm{r}_{t} \lambda /\left(I_{\mathrm{r}, \mathrm{DC}} f_{1}\right) \\
T_{\mathrm{e}}=\mathrm{r}_{\mathrm{f}} T_{1} / f_{1}=\mathrm{r}_{\mathrm{f}} / f_{1}^{2} \\
T_{\mathrm{r}}>T_{\mathrm{e}}
\end{array}\right.
$$

where $\lambda$ is the percentage range of the output duty cycle that can be varied to indicate the measured DC current, i.e. the duty cycle utilization. This was quite wide when the pulses in $v_{2}(t)$ were narrow as shown previously in Fig. 6. After adding $R_{2}$, the range is reduced as to be shown later. Therefore in the design $\lambda$ is set more conservatively. $r_{\mathrm{t}}$ is the target resolution (e.g. $1 \mathrm{~mA}$ ). $T_{\mathrm{r}}$ is the time in the sensor output waveform corresponding to the set resolution. Time $T_{\mathrm{e}}$ corresponds to the resolution of $f_{1}, r_{\mathrm{f}}(\mathrm{Hz})$ is the resolution of $f_{1}$, and $T_{1}=1 / f_{1}$.

In this study, a toroidal core made of permalloy $1 \mathrm{~J} 85$ is selected. The relative permeability around $50 \mathrm{~Hz}$ is 120000 , and the saturation flux density, $B_{\mathrm{s}}$, is $0.7 \mathrm{~T}$. Its cross-sectional area is $3.91 \mathrm{~mm}^{2}$, and the average flux path is $50.39 \mathrm{~mm}$. The triangle-wave generator is made of IC AD9833 whose frequency can be set with a resolution $\left(r_{\mathrm{f}}\right)$ of $0.004 \mathrm{~Hz}$. The DSP is TMS320F28335 with a clock frequency of $150 \mathrm{MHz}$. $\lambda$ is set at 0.1 . Substituting $\lambda=0.1$, $r_{t}=1 \mathrm{~mA}, r_{\mathrm{f}}=0.004 \mathrm{~Hz}$, and $I_{\mathrm{r}, \mathrm{DC}}=1.2$ A into (11) gives $f_{1}>48$ $\mathrm{Hz}$. Because the frequency of high-frequency current $(20$ $\mathrm{kHz}$ ) should better be divisible by $f_{1}$ to ensure that the average of the high-frequency current in a triangle-wave period is zero, $f_{1}$ is set to $50 \mathrm{~Hz}$. That is, when the frequency of the triangle-wave generator is $50 \mathrm{~Hz}$, the resolution of the sensor can meet the requirement.

\section{Design for range}

In this study, the parameters of the sensor are adjusted to provide the range and minimize the power loss which can be calculated as Eq. (12).

$$
P_{\text {loss }}=\frac{i_{1 \mathrm{p}}^{2}\left(N_{1} R_{0}+R_{1}\right)}{3}+\frac{i_{\mathrm{L} 2 \mathrm{p}}^{2}\left(N_{2} R_{0}+R_{2}\right)}{3}+i_{\mathrm{h} 2 \mathrm{p}}^{2}\left(N_{2} R_{0}+R_{2}\right)
$$

where $R_{0}$ is single-turn coil resistance, about $0.0275 \Omega$. Because $i_{1 \mathrm{p}}$ and $i_{\mathrm{L} 2 \mathrm{p}}$ are for triangle-wave currents, they are 
divided by $\sqrt{3}$ when calculating power. Due to the resistance of $W_{1}$ being already enough, $R_{1}$ is set to $0 \Omega$.

$i_{1 \mathrm{p}}, i_{\mathrm{L} 2 \mathrm{p}}, i_{\mathrm{h} 2 \mathrm{p}}, R_{2}, N_{1}$ and $N_{2}$ from (12) need to be calculated for meeting the range at first. Then the core must be saturated to realize the fluxgate function. Finally, calculating power loss. Fig. 16 demonstrates the flowchart of calculation. The meaning of each formula is explained below.

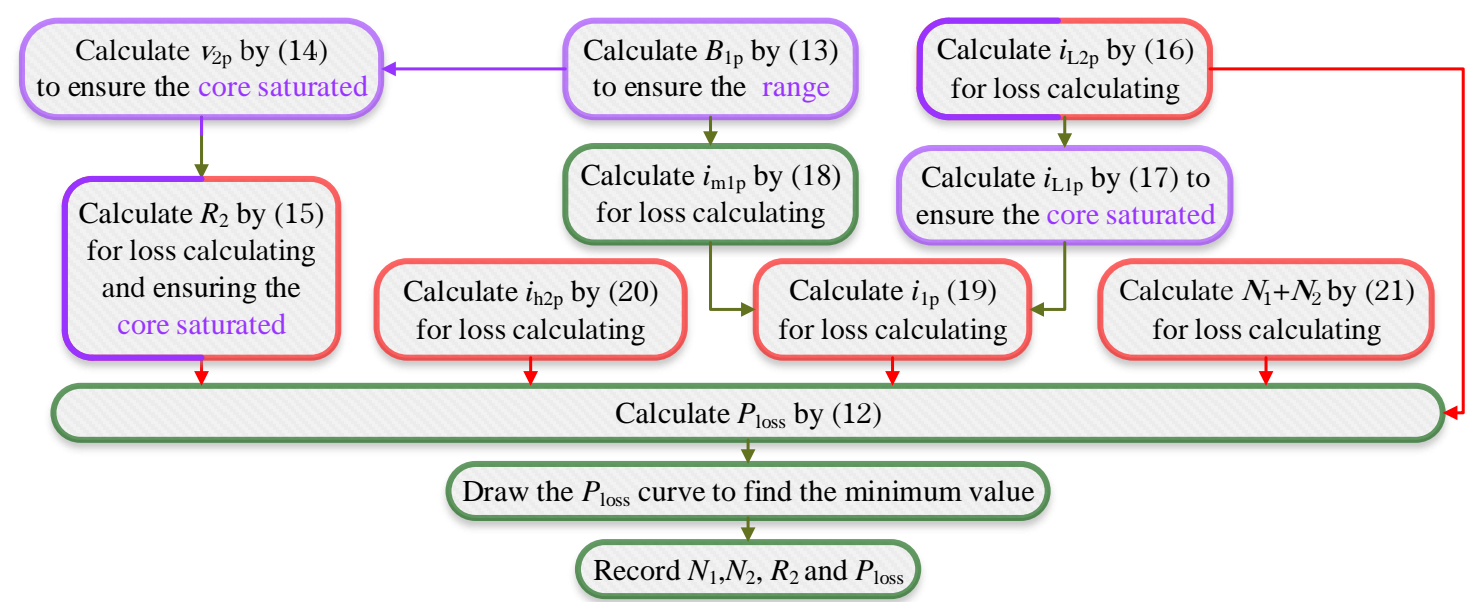

Fig. 16 Flowchart of power loss calculation. (13) is to meet the range requirement. (14)-(17) are to make the core saturate. (15)-(21) and (12) are to calculate the power loss.

As stated in part A section II, the range of the sensor is determined by the difference between $B_{1 \mathrm{p}}$ and $B_{\mathrm{s}}$. If the $B_{1 \mathrm{p}}$ meets (13), the range can meet the requirement.

$$
I_{\mathrm{r}, \mathrm{DC}}=\left(B_{\mathrm{lp}}-B_{\mathrm{s}}\right) l_{c} /\left(\mu_{0} \mu_{r} N_{0}\right)
$$

Case (2) in part C of section II mentions that $B_{1 \mathrm{p}}$ is determined by $R_{2}$ and $i_{\mathrm{L} 1 \mathrm{p}}$, and $v_{2 \mathrm{p}}$ is used to indicate whether the core is saturated. $v_{2 \mathrm{p}}$ and $B_{1 \mathrm{p}}$ satisfy

$$
v_{2 \mathrm{p}}=B_{1 \mathrm{p}} /\left(m N_{2} A_{\mathrm{c}} f_{\mathrm{s}}\right)
$$

The relationship between $v_{2 \mathrm{p}}$ and $R_{2}$ is

$$
R_{2}=v_{2 \mathrm{p}} / i_{\mathrm{L} 2 \mathrm{p}}
$$

To attenuate the impact of the high-frequency effect, $v_{\mathrm{h} 2 \mathrm{p}}$ is set to be less than $1 \%$ of $v_{2 \mathrm{p}}$ after filtering. A fourth-order low-pass filter is implemented in two stages with attenuation of $0.3 \%$, i.e. after passing through the low-pass filters $v_{\mathrm{h} 2 \mathrm{p}}$ is $0.3 \%$ of the original value. The relationship of $v_{\mathrm{h} 2 \mathrm{p}}$ and $v_{2 \mathrm{p}}$ finally reduces to the relationship between $i_{\mathrm{L} 2 \mathrm{p}}$ and $i_{\mathrm{hop}}$.

$$
\left\{\begin{array}{l}
k_{\mathrm{L}} v_{\mathrm{h} 2 \mathrm{p}}=k_{\mathrm{H}} v_{2 \mathrm{p}} \\
v_{\mathrm{h} 2 \mathrm{p}}=i_{\mathrm{h} 2 \mathrm{p}} R_{2} \\
v_{2 \mathrm{p}}=i_{\mathrm{L} 2 \mathrm{p}} R_{2} \\
i_{\mathrm{h} 2 \mathrm{p}}=i_{\mathrm{h} 0 \mathrm{p}} N_{0} / N_{2}
\end{array} \Rightarrow i_{\mathrm{L} 2 \mathrm{p}}=\frac{i_{\mathrm{h} 0 \mathrm{p}} k_{\mathrm{H}} N_{0}}{k_{\mathrm{L}} N_{2}}\right.
$$

where $k_{\mathrm{L}}$ is the filter attenuation ratio, i.e. $0.3 \%$. $k_{\mathrm{H}}$ is the set ratio, i.e. $1 \%$. When the $\mathrm{DAB}$ is fully loaded, the peak value of its secondary winding current is about 15 A, i.e. $i_{\mathrm{h} 0 \mathrm{p}}=15 \mathrm{~A}$.

The relationship between $i_{\mathrm{L} 1 \mathrm{p}}$ and $i_{\mathrm{L} 2 \mathrm{p}}$ is

$$
i_{\text {L1p }}=i_{\text {L2p }} N_{2} / N_{1}
$$

$i_{\mathrm{mlp}}$ is estimated by (18) which can ensure that $i_{1}(t)$ can meet the range when there

$$
i_{\mathrm{mlp}}=B_{1 \mathrm{p}} l_{c} /\left(\mu_{0} \mu_{\mathrm{r}} N_{1}\right)
$$

Ignore the phase difference between $i_{\mathrm{m} 1}(t)$ and $i_{\mathrm{L} 1}(t)$, and use $i_{\mathrm{m} 1 \mathrm{p}}+i_{\mathrm{L} 1 \mathrm{p}}$ to estimate $i_{\mathrm{p}}$ as

$$
i_{1 \mathrm{p}}=i_{\mathrm{mlp}}+i_{\mathrm{Llp}}
$$

The relationship between $i_{\mathrm{h} 2 \mathrm{p}}$ and $i_{\mathrm{h} 0 \mathrm{p}}$ is

$$
i_{\mathrm{h} 2 \mathrm{p}}=i_{\mathrm{hOp}} N_{0} / N_{2}
$$

To reduce parasitic capacitance, the sensor windings only have one layer on the toroidal core. Hence, $N_{1}+N_{2}$ is limited. The relationship between the winding wire diameter $d_{\mathrm{w}}$, the core inner perimeter $p_{\mathrm{c}}$ and $N_{1}+N_{2}$ is

$$
N_{1}+N_{2}=p_{c} / d_{w}
$$

In this study, the wire diameter is $0.1 \mathrm{~mm}$, and the inner circumference of the core is $48.4 \mathrm{~mm}$. Therefore, the total number of turns of the two windings is $N_{1}+N_{2}=484$.

Given a value of $N_{1}$, the power loss can be calculated according to (12)-(21). When $N_{1}$ changes from 10 to 300, the power loss is shown in Fig. 17. $N_{1}=87$ is the point of minimum power loss. Therefore $N_{2}=397, R_{2} \approx 120 \Omega, i_{1 \mathrm{p}} \approx 70$ $\mathrm{mA}, v_{2 \mathrm{p}} \approx 1.4 \mathrm{~V}$ and $P_{\text {loss }} \approx 0.2 \mathrm{~W}$.

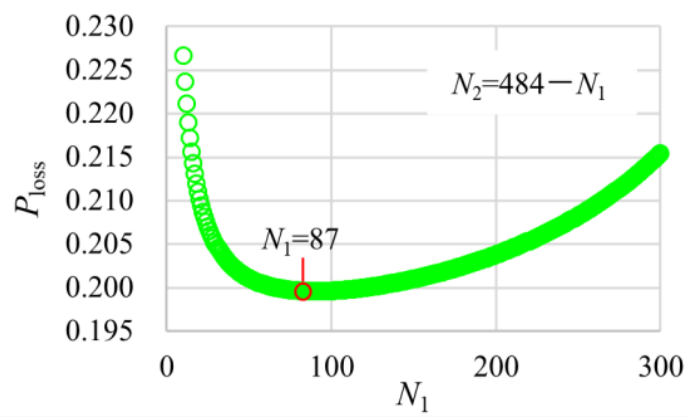

Fig. 17 Power loss curve when $N_{1}$ changes from 10 to 300 .

Fig. 18 shows a set of experimental results to verify the calculation. Fig. 18(a) and (b) are the results when no high-frequency $\mathrm{AC}$ current is present in $W_{0}$ but measured current $I_{\mathrm{DC}}$ is $0 \mathrm{~A}$ and $1.2 \mathrm{~A}$ respectively. Fig. 18(c) shows the result when there is $15 \mathrm{~A}$ peak high-frequency $\mathrm{AC}$ in $W_{0}$ but DC component is 0 A. In Fig. 18 (a), when $i_{1 \mathrm{p}}$ is $70 \mathrm{~mA}, v_{2 \mathrm{p}}$ is about $1.3 \mathrm{~V}$ which is close to the calculated value $(1.4 \mathrm{~V})$. In Fig. 18(b), $v_{2 \mathrm{p}}$ is still about $1.3 \mathrm{~V}$ but the waveform loses half-wave symmetry, and the duty cycle changes to $61.32 \%$ which is a change of about $10 \%(0.1)$, due to $I_{\mathrm{DC}}=1.2 \mathrm{~A}$. Fig. 18(c) shows the effect of filtering in the sensor output stage. High-frequency harmonics are suppressed so that the instantaneous peak value of the voltage across $W_{2}$ is low and the filtered voltage is similar to that in Fig. 18(a). 


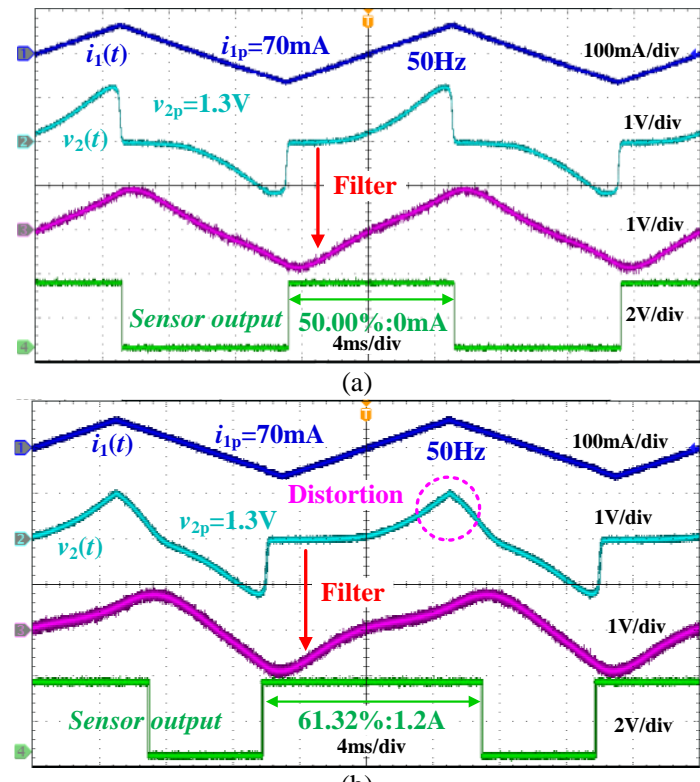

(b)

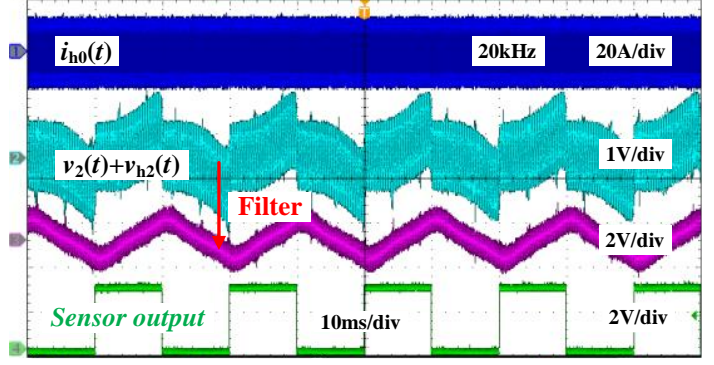

(c)

Fig. 18 Waveforms in sensor circuit (a)DAB no-load and $I_{\mathrm{DC}}=0 \mathrm{~A}$; (b) DAB no-load and $I_{\mathrm{DC}}=1.2 \mathrm{~A} ;$ (c) DAB is fully loaded and $I_{\mathrm{DC}}=0 \mathrm{~A}$.

\section{Sensor circuit}

The sensor circuit consists of two parts: the triangle-wave generator and the signal conditioning circuit, with functional blocks and components, as shown in Fig. 19. Photos of the sensor are shown in Fig. 20, with a $3 \mathrm{~cm} \times 3 \mathrm{~cm}$ PCB.

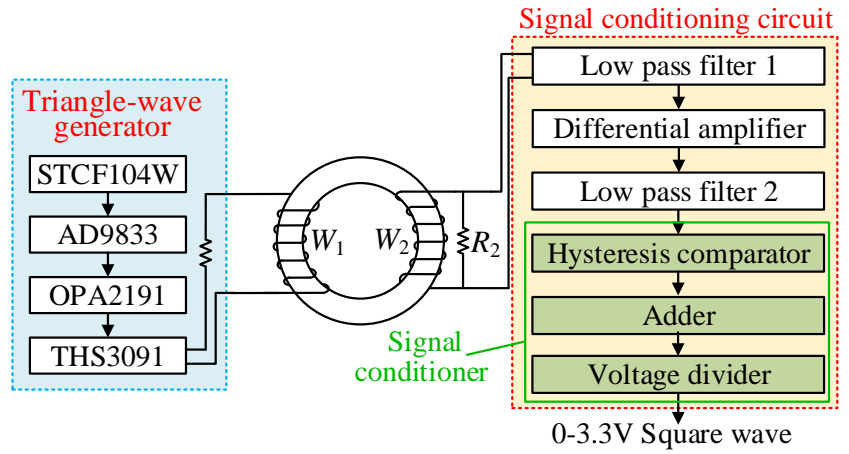

Fig. 19 Schematic diagram of the sensor circuit.

An 8-pin $8051 \mathrm{MCU}$ STCF104W is used to control the AD9833. It is necessary to remove the DC bias in the output of AD9833 by op-amp OPA2191 which has low-temperature dependency and power consumption. However, OPA2191 cannot provide the required current. Amplifier THS3901 is then used with a maximum output of $\pm 250 \mathrm{~mA}$.

The signal conditioning circuit consists of three parts: two low pass filters, a differential amplifier and then the signal conditioner containing a hysteresis comparator, an adder and a voltage divider. The total power consumption of two parts of the electronic circuit is about $0.505 \mathrm{~W}$. With $P_{\text {loss }}$ of $0.2 \mathrm{~W}$, the maximum power loss is $0.705 \mathrm{~W}$.

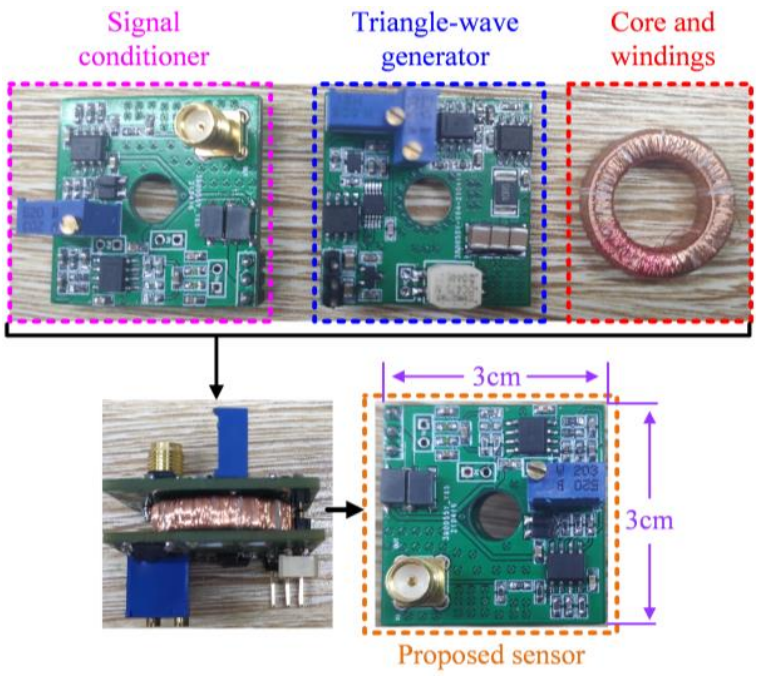

Fig. 20 Pictures of the current sensor

\section{E. Calibration}

The sensor is calibrated by a higher precision instrument before it is used. In this way, it can be determined whether the sensor meets the design specifications.

A high-precision multimeter, Fluke $8846 \mathrm{~A}$ with error and resolution down to $100 \mathrm{pA}$, is first used to calibrate the designed sensor under pure DC. Adjust the DC current that flows through $W_{0}$ to make the reading of the multimeter to be $1 \mathrm{~mA}$. Under this circumstance, the value of DSP counter will change. The change is used as a standard of $1 \mathrm{~mA}$ to calculate the measured current. Then adjusting the DC current, in steps of $1 \mathrm{~mA}$ in $[-10 \mathrm{~mA}, 10 \mathrm{~mA}]$ and larger at higher current levels. Comparing the output of the sensor, measured from the duty cycle, with the multimeter reading, the difference is the measurement error of the sensor. The result is plotted in Fig. 21. The sensor output is sensitive and almost proportional to DC current measured. A straight line can be used to curve fit the results. The discrepancy of curve fitting shows that the error and resolution could be as small as $1 \mathrm{~mA}$.

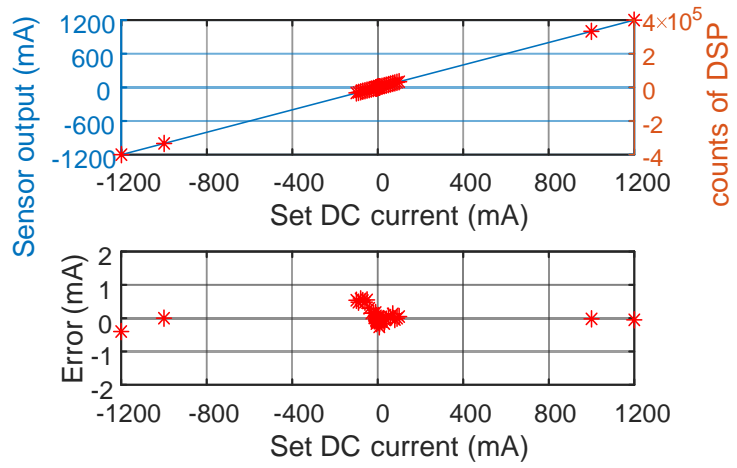

Fig. 21 Verification of sensor accuracy and resolution.

After the sensor is calibrated under pure DC, it is necessary to test whether the output would be affected by the $20 \mathrm{kHz}$ high-frequency AC current. Fig. 22 shows the test circuit. The secondary side of the DAB transformer is temporarily connected to a resistive load, and a high-frequency current is produced by the primary side H-bridge. Because the transformer blocks DC, the secondary side will generate a pure AC current which is mixed with the DC current by passing through the same core of the 
designed sensor. The magnitudes of the AC and DC components are changed to see whether the output of the sensor is the same as that in pure DC calibration.

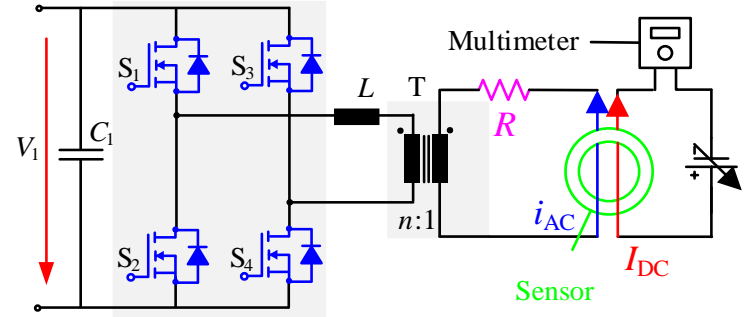

Fig. 22 Test circuit diagram.

Set the DC current at $0, \pm 1 \mathrm{~mA}$ or $\pm 1.2 \mathrm{~A}$. At each point, the AC current changes from 0 to $15 \mathrm{~A}$ peak with a step of 1 A. The measurement errors are shown in Fig. 23 with the maximum occurring at full DAB load current and sensor full scale. As shown in Fig. 23, when the DC current does not change, as the AC current increases from small to large, the error increases. When the $\mathrm{AC}$ is constant, the error increases with the increase of the DC current. But the resolution did not change during the process. The maximum error is $4 \mathrm{~mA}$ at $\mathrm{AC}$ is $15 \mathrm{~A}$, therefore, the proposed method can be applied from low current to high current.

The maximum error is about $4 \mathrm{~mA}$, implying the accuracy of proposed sensor is $0.33 \%$ which is a little bigger than the LAH $12(0.3 \%)$ in TABLE I. LAH 12 is a current sensor that comes closest in accuracy and range to the proposed sensor. When using the same DSP (TMS320F28335) to measure the proposed sensor and LAH 12 (whose measuring resistance is $200 \Omega$ ), the resolution of proposed sensor and LAH 12 is $1 \mathrm{~mA}$ and $7.3 \mathrm{~mA}$, respectively. Therefore, the resolution of proposed sensor is better.

When using LAH 12 to measure the primary winding current (about 7.5 A), the error is $22.5 \mathrm{~mA}$. When using it to measure secondary winding current (about $15 \mathrm{~A}$ ), the error is $45 \mathrm{~mA}$. Both of them are more than the error of proposed sensor. Therefore, LAH 12 has no superiority in the elimination of DC bias.



Fig. 23 Sensor output under different peak values of $20 \mathrm{kHz}$ current.

The step response of the sensor is shown in Fig. 24. The measured DC current changes from 0 to $1 \mathrm{~A}$. The response time of the sensor is between $10 \mathrm{~ms}$ and $40 \mathrm{~ms}$. Therefore, the step response time is defined as $40 \mathrm{~ms}$ which is fast enough for DC bias elimination control.

To prove the steadiness of the sensor, Fig. 25 is obtained by recording the sensor output every second for 30 minutes, using the arrangement shown in Fig. 22 with three DC and AC combinations. Fig. 25(a) shows that the sensor's zero drift is less than $0.5 \mathrm{~mA}$. Fig. 25 (b) shows that the maximum error is less than $1 \mathrm{~mA}$ when the measured DC current is 100 mA. Fig. 25(c) shows that the maximum error is less than 1.5 $\mathrm{mA}$ when the measured current includes $100 \mathrm{~mA} \mathrm{DC}$ and 15 A $20 \mathrm{kHz}$ AC. The reason why sensor steadiness is not tested at $1.2 \mathrm{~A}$ is that as DC bias elimination control is activated, DC current will decrease. To virtually eliminate the DC, it is necessary to measure accurately when DC current is small. $100 \mathrm{~mA}$ is chosen arbitrarily in this study.

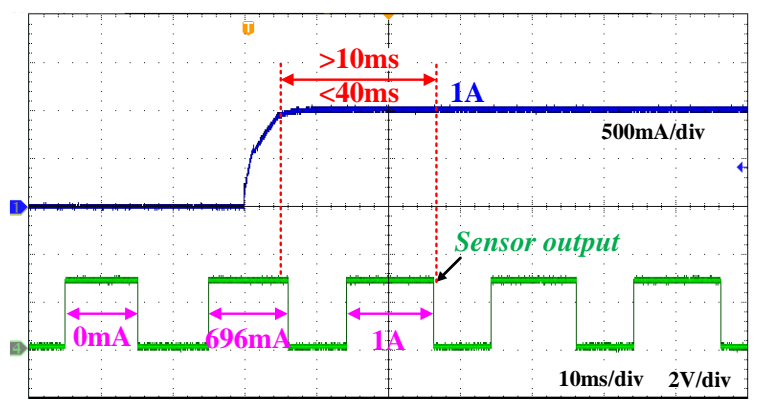

Fig. 24 Step response of the sensor.

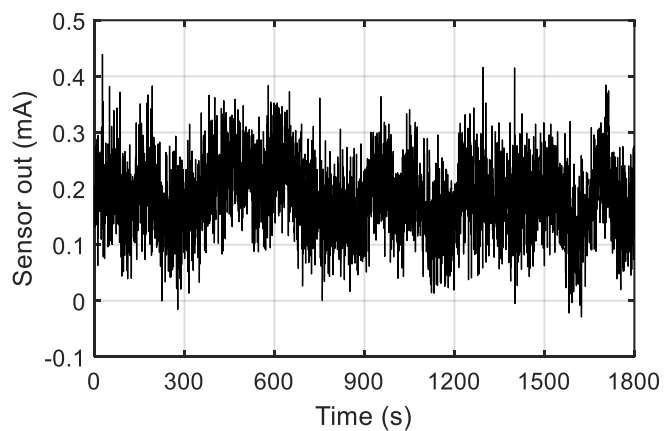

(a)

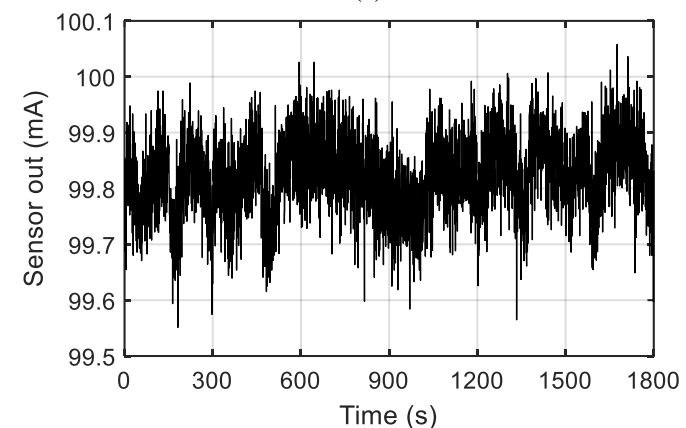

(b)

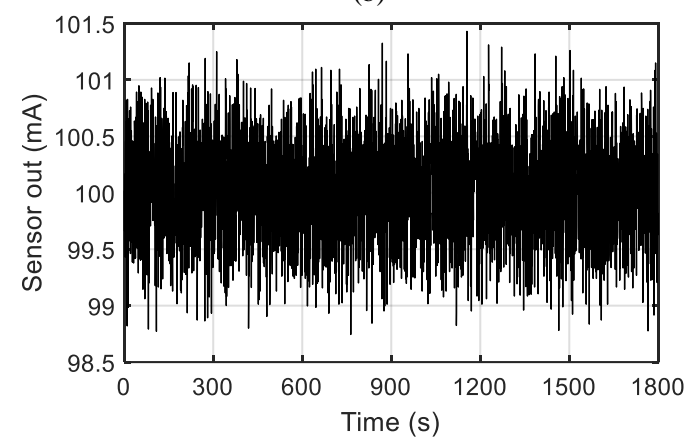

(c)

Fig. 25 Sensor output in 30 minutes, using the experimental method of Fig. 22. (a) without measured current; (b) with $100 \mathrm{~mA} \mathrm{DC}$; (c) with $100 \mathrm{~mA} \mathrm{DC}$ and $15 \mathrm{~A}$ (peak) $20 \mathrm{kHz} \mathrm{AC}$.

Based on the insight into the working principle of a single-core fluxgate sensor and characteristics of the target DAB circuit, this study has proposed to add a suitable resistor and a low pass filter on the output side of the sensor 
which can then measure a small DC component mixed in a large AC current. In design, the required parameters can be calculated by putting the target parameters into the algorithm. The signal conditioning circuit of this sensor is of a common configuration. Hence, the design can be extrapolated to different applications. The cost of this sensor is about \$19 while that of the comparable LAH 12 is \$23 which cannot achieve the same absolute accuracy.

\section{DAB DC BIAS ELIMINATION EXPERIMENT RESULTS}

Because the DC component is a small part of the winding current, eliminating it in the two windings is not easy to illustrate. However, the DC component in the magnetizing current can be more clearly shown. Therefore, the DC components in the magnetizing (viewed from the secondary side) and primary winding currents are thus measured and eliminated to demonstrate the concept of control. The block diagram is shown in Fig. $26(n=2)$. The output of the PI block, $\Delta d$, is added to the duty cycle of the H-bridge to adjust the small DC voltage applied to the winding.



Fig. 26 Control block diagram to eliminate DC bias.

The experiment is conducted on the $1 \mathrm{~kW}$ DAB circuit as detailed in TABLE II. As the duty cycle change is going to be small in the output of the proposed current sensor, commercial current probes of the type Cybertek CP8050A are used to display the waveforms and help demonstrate the effect of control. The commercial probes are also used as control feedback for comparison. The losses and efficiencies of the transformer and the entire $\mathrm{DAB}$ converter are measured in both current sensor arrangements.

CP8050A is a Hall effect current probe whose accuracy is abour $3 \%$ at $20 \mathrm{kHz}$. Its range is set down to $7.5 \mathrm{~A}$. It is possible to share the output of the CP8050A current probe between two channels, one connected to an oscilloscope, and the other to the DSP as control feedback. Fig. 27 shows the results of different cases. TABLE III shows the power losses as well as efficiencies $(\eta)$ of the DAB and transformer $(\mathrm{T})$, measured by a wideband width, Yokogawa WT5000 power analyzer.

Fig. 27(a) shows the experimental results when the proposed fluxgate-based current sensors are used in the closed-loop control. The current waveforms (Chanel 1 and 2) are captured by CP8050A. The DC components in the magnetizing (viewed from the secondary side) and primary winding currents are $-5 \mathrm{~mA}$ and $8 \mathrm{~mA}$ respectively, measured from the duty cycle of the proposed sensor's output. They are small as the closed-loop control attempts to eliminate them. The DC components computed from the waveforms of CP8050A current sensors are greater because of errors.

Fig. 27(b) shows the results when CP8050A probes are used for feedback. The DC components in the captured waveforms are reduced. But those measured from the duty cycle of the proposed sensor are far greater, $36 \mathrm{~mA}$ and 259 $\mathrm{mA}$ respectively. Based on that the accuracy of the proposed sensor has been validated, this shows that feedback control with inaccurate sensing would actually cause extra DC bias.

TABLE III

DAB AND TRANSFORMER LOSS CORRESPONDING TO FIG. 27 AND FIG. 28

\begin{tabular}{ccccc}
\hline & $\mathrm{T}_{\text {loss }}(\mathrm{W})$ & $\mathrm{DAB}_{\text {loss }}(\mathrm{W})$ & $\eta_{\mathrm{T}}$ & $\eta_{\mathrm{DAB}}$ \\
\hline Fig. 27 (a) & 11.32 & 61.12 & $99.13 \%$ & $94.29 \%$ \\
Fig. 27 (b) & 11.55 & 62.93 & $99.09 \%$ & $94.17 \%$ \\
Fig. 28 without control & 13.60 & 70.67 & $98.90 \%$ & $93.43 \%$ \\
Fig. 28 with control & 11.45 & 61.34 & $99.13 \%$ & $94.29 \%$ \\
\hline
\end{tabular}

The DAB transformer is at a higher level of DC bias in the case corresponding to Fig. 27(b). But in TABLE III the power loss is only modestly increased as compared to the case of Fig. 27(a). This is because a large margin has been reserved in the $\mathrm{DAB}$ transformer design. If the margin is reduced in the future, the effect of eliminating DC bias would be greater.

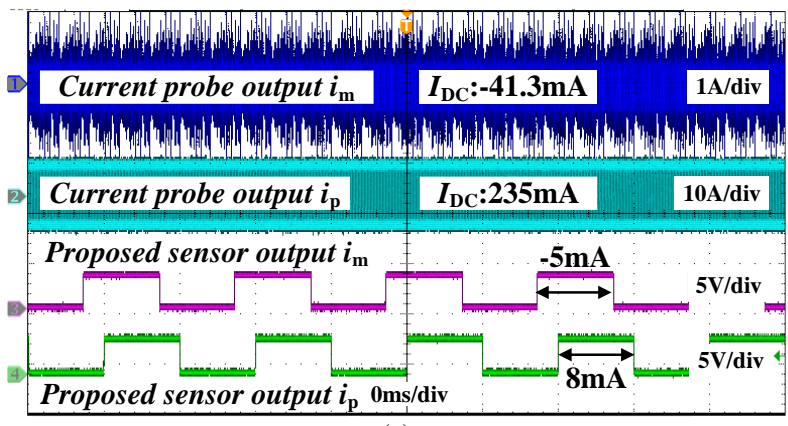

(a)

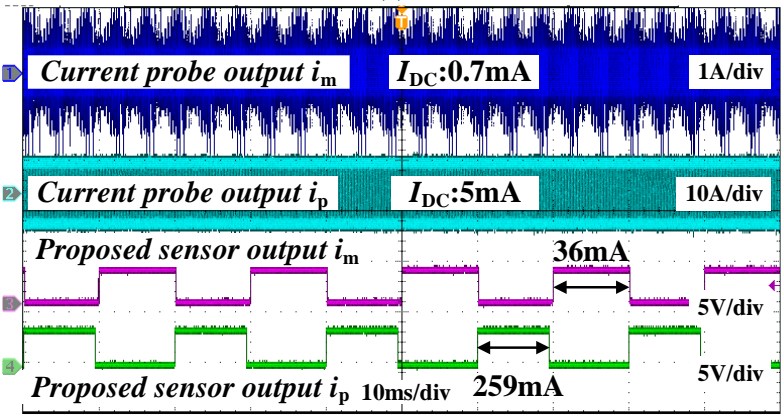

(b)

Fig. 27 DC bias elimination control with feedback from (a) the proposed sensors and (b) commercial current probes CP8050A. Channels from top down: magnetizing current $\left(i_{\mathrm{m}}\right)$ captured by CP8050A; primary winding current $\left(i_{\mathrm{p}}\right)$ captured CP8050A; DC in magnetizing current $\left(i_{\mathrm{m}}\right)$ measured by the output duty cycle of the proposed sensor; DC in the primary winding current $\left(i_{\mathrm{p}}\right)$ measured by output duty cycle proposed sensor.

Fig. 28 shows the dynamic response of eliminating DC bias using the proposed sensor. The magnetizing current waveform, still captured by CP8050A, is apparently aliased on the oscilloscope because of the large sample size. The actual waveform is extracted from the saved data as zoom-in plots in the figure. 
To avoid hunting in digital control, a dead zone of [-10 $\mathrm{mA}, 10 \mathrm{~mA}]$ is introduced. Only when the measured DC component exceeds this dead zone will the controller be activated. This is one of the reasons why the DC in the magnetizing current is not completely eliminated.

Approximately, the first $100 \mathrm{~ms}$ shown in Fig. 28 is the case when the controller is arbitrarily prohibited. The winding current contains a DC component of about $45 \mathrm{~mA}$ and the magnetizing current contains a DC component of about $668 \mathrm{~mA}$ (viewed from the secondary side). The loss of the DAB is high (TABLE III). This is because the DC components are additional and superimposed on the original $\mathrm{AC}$ currents and hence will increase the loss. The reason why the loss is less significant in the transformer is that the winding resistance is small. The on-resistance of devices in the $\mathrm{DAB} \mathrm{H}$-bridges is greater than the resistance of the transformer windings. As a result, the loss effect of the DC components on the DAB H-bridges is more noteworthy.

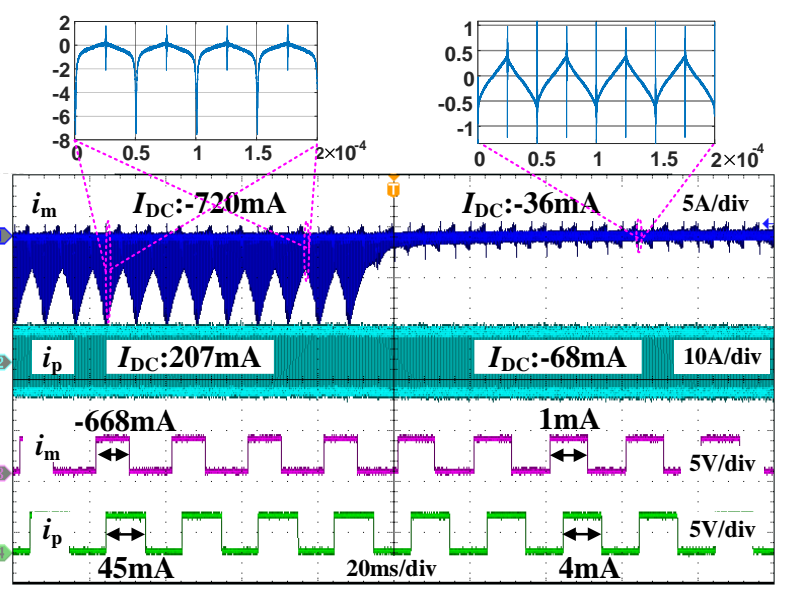

Fig. 28 Demonstration of dynamic DC elimination control. Channels from top down: magnetizing current $\left(i_{\mathrm{m}}\right)$ captured by CP8050A; primary winding current $\left(i_{\mathrm{p}}\right)$ captured CP8050A; DC in magnetizing current $\left(i_{\mathrm{m}}\right)$ measured by the output duty cycle of the proposed sensor; DC in the primary winding current $\left(i_{\mathrm{p}}\right)$ measured by output duty cycle proposed sensor

To further analyze the relationship between the DC bias and transformer loss, the loss was measured with the power analyzer under different DC bias conditions. The results are shown in Fig. 29. It is found that when the DC component of the magnetizing current is less than $200 \mathrm{~mA}$ the loss is almost constant. But when the bias is over $200 \mathrm{~mA}$ the loss begins to increase quickly. This is consistent with the allowable DC current of windings calculated in the previous section. When the flux density reaches the non-linear region of the B-H curve, the loss increases. In this study, the margin of the magnetic core area is relatively large; the allowable DC component of the magnetizing current is about $200 \mathrm{~mA}$. With the proposed sensor, this margin can be reduced, thereby reducing the size of the DAB transformer.



(a)



(b)

Fig. 29 Effect of DC bias on (a) transformer loss and (b) efficiency.

\section{CONCLUSION}

$\mathrm{DC}$ bias in the DAB circuit and transformer is one of the main issues affecting the performance of a DAB DC-DC converter system. In this study, the difficulty of DC bias measurement is analyzed. A new current sensor that can accurately measure a small DC component mixed in a large high-frequency $\mathrm{AC}$ current is proposed. It works on the principle of a fluxgate sensor to achieve the needed sensitivity and accuracy by making use of the large change of core permeability due to saturation. The potentially large voltage induced by the high-frequency AC current is dealt with by integrating a suitable load resistor to hybridize a current transformer in the instrumentation device. A design is exemplified, for the resolution of $1 \mathrm{~mA}$ and DC measurement range of $\pm 1.2 \mathrm{~A}$, illustrating the potential effectiveness of the concept. When measuring DC mixed in high-frequency AC current with a peak of about $15 \mathrm{~A}$, the maximum error recorded is about $4 \mathrm{~mA}$. This ensures the quality of feedback control to eliminate (reduce) the DC current component, which is demonstrated by experiments.

\section{ACKNOWLEDGMENT}

This work was supported by the National Key Research and Development Program of China under Grant 2018 YFB0905803.

\section{REFERENCES}

[1] L. Zheng et al., "SiC-Based 5-kV Universal Modular Soft-Switching Solid-State Transformer (M-S4T) for Medium-Voltage DC Microgrids and Distribution Grids," in IEEE Transactions on Power Electronics, vol. 36, no. 10, pp. 11326-11343, Oct. 2021, doi: 10.1109/TPEL.2021.3066908.

[2] Z. Zhang, Y. Cai, Y. Zhang, D. Gu and Y. Liu, "A Distributed Architecture Based on Microbank Modules With Self-Reconfiguration Control to Improve the Energy Efficiency in the Battery Energy Storage System," in IEEE Transactions on Power Electronics, vol. 31, no. 1, pp. 304-317, Jan. 2016, doi: 10.1109/TPEL.2015.2406773.

[3] S. A. Assadi, H. Matsumoto, M. Moshirvaziri, M. Nasr, M. S. Zaman and O. Trescases, "Active Saturation Mitigation in High-Density Dual-Active-Bridge DC-DC Converter for On-Board EV Charger Applications," in IEEE Transactions on Power Electronics, vol. 35, no. 4, pp. 4376-4387, April 2020, doi: 10.1109/TPEL.2019.2939301.

[4] F. An, W. Song, B. Yu and K. Yang, "Model Predictive Control With Power Self-Balancing of the Output Parallel DAB DC-DC Converters in Power Electronic Traction Transformer," in IEEE Journal of Emerging and Selected Topics in Power Electronics, vol. 6, no. 4, pp. 1806-1818, Dec. 2018, doi: 10.1109/JESTPE.2018.2823364.

[5] D. Mou, Q. Luo, J. Li, Y. Wei and P. Sun, "Five-Degree-of-Freedom Modulation Scheme for Dual Active Bridge DC-DC Converter," in IEEE Transactions on Power Electronics, vol. 36, no. 9, pp. 10584-10601, Sept. 2021, doi: 10.1109/TPEL.2021.3056800.

[6] P. Yao, X. Jiang, P. Xue, S. Li, S. Lu and F. Wang, "Design 
Optimization of Medium Frequency Transformer for DAB Converters with DC Bias Capacity," in IEEE Journal of Emerging and Selected Topics in Power Electronics, doi: 10.1109/JESTPE.2020.3010155.

[7] J. Imaoka, K. Okamoto, S. Kimura, M. Noah, W. Martinez, M. Yamamoto and M. Shoyama, "A Magnetic Design Method Considering DC-Biased Magnetization for Integrated Magnetic Components Used in Multiphase Boost Converters," in IEEE Transactions on Power Electronics, vol. 33, no. 4, pp. 3346-3362, April 2018, doi: 10.1109/TPEL.2017.2707385.

[8] J. Muhlethaler, J. Biela, J. W. Kolar and A. Ecklebe, "Core Losses Under DC Bias Condition Based on Steinmetz Parameters," in IEEE Transactions on Power Electronics, vol. 27, no. 2, pp. 953-963, Feb. 2012, doi: 10.1109/TPEL.2011.2160971.

[9] M. Wattenberg, U. Schwalbe and M. Pfost, "Impact of DC-Bias on Dual Active Bridge Control and How to Avoid it," 2019 21st European Conference on Power Electronics and Applications (EPE '19 ECCE Europe), 2019, pp. P.1-P.8, doi: 10.23919/EPE.2019.8915516.

[10] L. Shu, W. Chen and Z. Song, "Prediction method of DC bias in DC-DC dual-active-bridge converter," in CPSS Transactions on Power Electronics and Applications, vol. 4, no. 2, pp. 152-162, June 2019, doi: 10.24295/CPSSTPEA.2019.00015.

[11] Y. Xuan, X. Yang, W. Chen, T. Liu and X. Hao, "A Novel NPC Dual-Active-Bridge Converter With Blocking Capacitor for Energy Storage System," in IEEE Transactions on Power Electronics, vol. 34, no. 11, pp. 10635-10649, Nov. 2019, doi: 10.1109/TPEL.2019.2898454

[12] T. Zhu, F. Zhuo, F. Zhao, F. Wang, H. Yi and T. Zhao, "Optimization of Extended Phase-Shift Control for Full-Bridge CLLC Resonant Converter With Improved Light-Load Efficiency," in IEEE Transactions on Power Electronics, vol. 35, no. 10, pp. 11129-11142, Oct. 2020, doi: 10.1109/TPEL.2020.2978419.

[13] P. Liu and S. Duan, "A ZVS Range Enhancement Strategy for DAB Converter by Using Blocking Capacitors," in IEEE Journal of Emerging and Selected Topics in Power Electronics, vol. 9, no. 2, pp. 1389-1398, April 2021, doi: 10.1109/JESTPE.2020.3016052.

[14] B. Zhao, Q. Song, W. Liu and Y. Sun, "Overview of Dual-Active-Bridge Isolated Bidirectional DC-DC Converter for High-Frequency-Link Power-Conversion System," in IEEE Transactions on Power Electronics, vol. 29, no. 8, pp. 4091-4106, Aug. 2014, doi: 10.1109/TPEL.2013.2289913.

[15] Q. Bu and $\mathrm{H}$. Wen, "Control Strategies for Dc-bias Current Elimination in Dual-Active-Bridge DC-DC Converter: An Overview," 2020 IEEE/IAS Industrial and Commercial Power System Asia (I\&CPS Asia), 2020, pp. 1155-1162, doi: 10.1109/ICPSAsia48933.2020.9208573.

[16] Yunpeng Yao, Shen Xu, Weifeng Sun and Shengli Lu. "A novel compensator for eliminating DC magnetizing current bias in hybrid modulated dual active bridge converters." Journal of Power Electronics, vol. 16, no. 5, pp.1650-1660, 2016, doi: 10.6113/JPE.2016.16.5.1650

[17] J. Cho, K. Park, J. Park, G. Moon and M. Youn, "Design of a Digital Offset Compensator Eliminating Transformer Magnetizing Current Offset of a Phase-Shift Full-Bridge Converter," in IEEE Transactions on Power Electronics, vol. 27, no. 1, pp. 331-341, Jan. 2012, doi: 10.1109/TPEL.2011.2158115.

[18] B. P. Baddipadiga and M. Ferdowsi, "Dual loop control for eliminating DC-bias in a DC-DC dual active bridge converter," 2014 International Conference on Renewable Energy Research and Application (ICRERA), Milwaukee, WI, 2014, pp. 490-495, doi: 10.1109/ICRERA.2014.7016433.

[19] S. Dutta, S. Bhattacharya and M. Chandorkar, "A novel predictive phase shift controller for bidirectional isolated dc to dc converter for high power applications," 2012 IEEE Energy Conversion Congress and Exposition (ECCE), Raleigh, NC, 2012, pp. 418-423, doi: 10.1109/ECCE.2012.6342791.

[20] H. R. Weischedel and G. R. Westerman, "A Symmetry Correcting Pulsewidth Modulator for Power Conditioning Applications," in IEEE Transactions on Industry Applications, vol. IA-9, no. 3, pp. 318-322, May 1973, doi: 10.1109/TIA.1973.349909.

[21] K. H. Andersen and M. Nymand, "Digital estimating and balancing of transformer magnetizing current in an isolated full bridge converter," 2017 IEEE Southern Power Electronics Conference (SPEC), Puerto Varas, 2017, pp. 1-6, doi: 10.1109/SPEC.2017.8333616.

[22] S. Han, I. Munuswamy and D. Divan, "Preventing transformer saturation in bi-directional dual active bridge buck-boost DC/DC converters," 2010 IEEE Energy Conversion Congress and Exposition, Atlanta, GA, 2010, pp. 1450-1457, doi: 10.1109/ECCE.2010.5618254.

[23] B. Jia, C. Du, C. c. Song, J. Lin and Q. Liu, "DC Bias Suppression Strategy in Dual Active Bridge Based on Triple Phase Shift Control," 2018 Chinese Automation Congress (CAC), Xi'an, China, 2018, pp. 4282-4287, doi: 10.1109/CAC.2018.8623216.

[24] Z. Wang, J. Chai and X. Sun, "Method to control flux balancing of high-frequency transformers in dual active bridge dc-dc converters," in The Journal of Engineering, vol. 2018, no. 17, pp. 1835-1843, 11 2018, doi: 10.1049/joe.2018.8338.

[25] Y. Panov, M. M. Jovanović and B. T. Irving, "Novel transformer-flux-balancing control of dual-active-bridge bidirectional converters," 2015 IEEE Applied Power Electronics Conference and Exposition (APEC), Charlotte, NC, 2015, pp. 42-49, doi: 10.1109/APEC.2015. 7104330

[26] B. Zhang, S. Shao, L. Chen, X. Wu and J. Zhang, "Steady-State and Transient DC Magnetic Flux Bias Suppression Methods for a Dual Active Bridge Converter," in IEEE Journal of Emerging and Selected Topics in Power Electronics, vol. 9, no. 1, pp. 744-753, Feb. 2021, doi: 10.1109/JESTPE.2019.2947299.

[27] S. Klopper and J. A. Ferreira, "A sensor for balancing flux in converters with a high-frequency transformer link," in IEEE Transactions on Industry Applications, vol. 33, no. 3, pp. 774-779, May-June 1997, doi: 10.1109/28.585868.

[28] K. Umetani, Y. Itoh and M. Yamamoto, "A detection method of DC magnetization utilizing local inhomogeneity of flux distribution in power transformer core," 2014 IEEE Energy Conversion Congress and Exposition (ECCE), Pittsburgh, PA, 2014, pp. 3739-3746, doi: 10.1109/ECCE.2014.6953909.

[29] G. Ortiz, J. Mühlethaler and J. W. Kolar, "'Magnetic Ear"-based balancing of magnetic flux in high power medium frequency dual active bridge converter transformer cores," 8th International Conference on Power Electronics - ECCE Asia, Jeju, 2011, pp. 1307-1314, doi: 10.1109/ICPE.2011.5944377.

[30] G. Ortiz, L. Fässler, J. W. Kolar and O. Apeldoorn, "Flux Balancing of Isolation Transformers and Application of "The Magnetic Ear" for Closed-Loop Volt-Second Compensation," in IEEE Transactions on Power Electronics, vol. 29, no. 8, pp. 4078-4090, Aug. 2014, doi: 10.1109/TPEL.2013.2294551.

[31] S. Dutta and S. Bhattacharya, "A method to measure DC bias in high-frequency isolation transformer of the dual active bridge DC to DC converter and its removal using current injection and PWM switching," 2014 IEEE Energy Conversion Congress and Exposition (ECCE), Pittsburgh, PA, 2014, pp. 1134-1139, doi: 10.1109/ECCE.2014.6953527.

[32] G. Buticchi and E. Lorenzani, "Detection Method of DC Bias in Distribution Power Transformers," in IEEE Transactions on Industrial Electronics, vol. 60, no. 8, pp. 3539-3549, Aug. 2013, doi: 10.1109/TIE.2012.2226418.

[33] Y. Panov, M. M. Jovanović and B. T. Irving, "Novel transformer-flux-balancing control of dual-active-bridge bidirectional converters," 2015 IEEE Applied Power Electronics Conference and Exposition (APEC), Charlotte, NC, 2015, pp. 42-49, doi: 10.1109/APEC.2015. 7104330.

[34] Y. Panov, M. M. Jovanović, L. Gang and M. Yueyong, "Transformer-flux-balancing control in isolated bidirectional DC-DC converters," 2014 IEEE Applied Power Electronics Conference and Exposition - APEC 2014, Fort Worth, TX, 2014, pp. 49-56, doi: 10.1109/APEC. 2014.6803288.

[35] A. Gertsman and S. Ben-Yaakov, "Zeroing transformer's DC current in resonant converters with no series capacitors," 2010 IEEE Energy Conversion Congress and Exposition, Atlanta, GA, 2010, pp. 4028-4034, doi: 10.1109/ECCE.2010.5618289.

[36] H. U. Auster, K. H. Glassmeier, W. Magnes, O. Aydogar, W. Baumjohann, D. Constantinescu, D. Fischer, K. H. Fornacon, E. Georgescu, P. Harvey, O. Hillenmaier, R. Kroth, M. Ludlam, Y. Narita, R. Nakamura, K. Okrafka, F. Plaschke, I. Richter, H. Schwarzl, B. Stoll, A. Valavanoglou and M. Wiedemann. "The THEMIS fluxgate magnetometer." Space Science Reviews, vol.141, no.1-4, pp.235-264, 2008, doi: 10.1007/s11214-008-9365-9.

[37] Kazimierczuk, Marian K. High-frequency magnetic components. John Wiley \& Sons, 2009.

[38] R. W. Erickson and D. Maksimovic, "A multiple-winding magnetics model having directly measurable parameters," PESC 98 Record. 29th Annual IEEE Power Electronics Specialists Conference (Cat. 
No.98CH36196), Fukuoka, Japan, 1998, pp. 1472-1478 vol.2, doi: 10.1109/PESC.1998.703254.

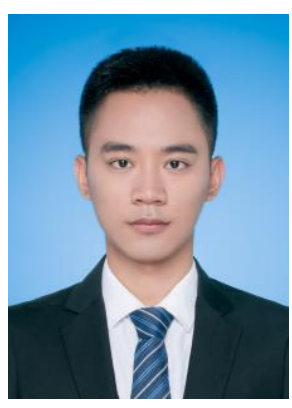

Guanqun Qiu (Student Member, IEEE) received his B.S. degree in electrical engineering from East China Jiaotong University, Jiangxi, China, in 2018. He is currently pursuing his Master's degree at Chongqing University, Chongqing, China. His research interests include $\mathrm{SiC}$ power converters and $\mathrm{SiC}$ device reliability.

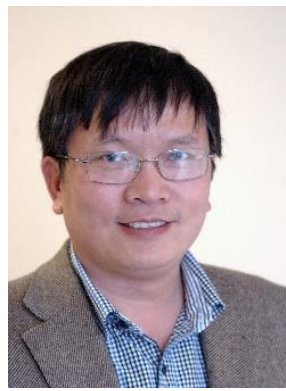

Li Ran (Senior Member, IEEE) received a Ph.D. degree in Power Systems Engineering from Chongqing University, Chongqing, China, in 1989. He was a Research Associate with the Universities of Aberdeen, Nottingham and Heriot-Watt, at Aberdeen, Nottingham and Edinburgh in the UK respectively. He became a Lecturer in Power Electronics with Northumbria University, Newcastle upon Tyne, the UK in 1999 and was seconded to Alstom Power Conversion, Kidsgrove, the UK in 2001. Between 2003 and 2012, he was with Durham University, the UK and took a sabbatical leave at MIT, the USA in 2007. He joined the University of Warwick, Coventry, the UK as a Professor in Power Electronics - Systems in 2012. His research interests include the applications of Power Electronics for electric power generation, delivery and utilization.

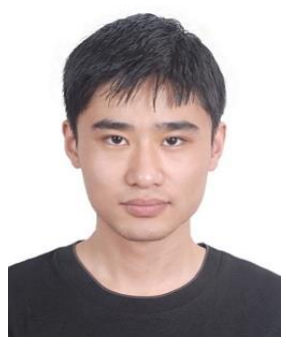

Hao Feng (Member, IEEE) received the B.S. degree and Ph.D. degrees from Huazhong University of Science and Technology, Wuhan, China, in 2013 and 2018, respectively. Since October 2018, he has been with the Future Renewable Electric Energy Delivery and Management (FREEDM) Systems Center, North Carolina State University, Raleigh NC, as a postdoctoral researcher. Since December 2020, he is an Associate Professor at Chongqing University, Chongqing, China. His research interests include medium voltage power conversion, $\mathrm{SiC}$ power converters and inductive power transfer systems.



Huaping Jiang received the $\mathrm{Ph}$. D. degree in Microelectronics at University of Electronic Science and Technology of China, China, in 2012. He was with Zhuzhou CRRC Times Electric Ltd., China, from 2013 to 2018. He was also with Dynex Semiconductor Ltd., Lincoln, U.K., from 2014 to 2018. From 2016 to 2018, he was a Visiting Fellow with University of Warwick, Coventry, U.K. He is currently a Research Fellow with Chongqing University, China. His current research interests include power semiconductor devices and their applications in power electronics.

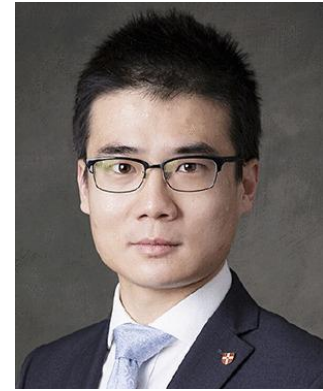

Teng Long (Member, IEEE) received the B.Eng. degree from the Huazhong University of Science and Technology, Wuhan, China, the B.Eng. (first class hons.) degree from the University of Birmingham, Birmingham, U.K., both in 2009, and the Ph.D. degree from the University of Cambridge, Cambridge, U.K., in 2013. Until 2016, he was a Power Electronics Engineer with the General Electric Power Conversion, Rugby, U.K. He is currently an associate professor with the University of Cambridge. His research interests include power electronics, electrical machines, and machine drives. Dr. Long is a Chartered Engineer registered with the Engineering Council in the U.K.



Andrew J. Forsyth (Senior Member, IEEE) received the B.Sc.(Eng) degree in electrical engineering from Imperial College, London, U.K., in 1981 and the Ph.D. degree in power electronics from the University of Cambridge, Cambridge, U.K., in 1987. He was a Design Engineer with GEC Electrical Projects Ltd from 1981 to 1983, a Lecturer at the University of Bath from 1986-1990, and a Lecturer / Senior Lecturer at Birmingham University from 1991 to 2004. Since 2004 he has been Professor of Power Electronics at The University of Manchester, Manchester U.K. His research interests include high-frequency converters, high-frequency magnetic components, modelling, control, and energy storage, particularly for aerospace and electric vehicle applications.

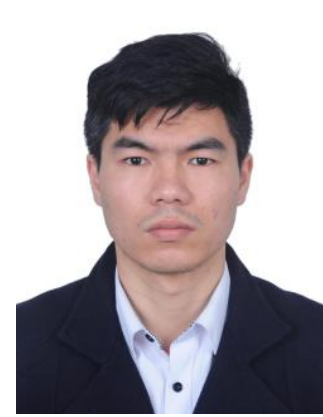

Weihua Shao received a $\mathrm{PhD}$ degree in electrical engineering from Chongqing University, Chongqing, China, in 2020. He is currently a Lecturer with Nanjing Institute of Technology. From 2017 to 2018, he was a joint PhD student with University of Warwick, Coventry, U.K. His research interests include advanced package of wide band gap power electronic devices and design of high power density converters.

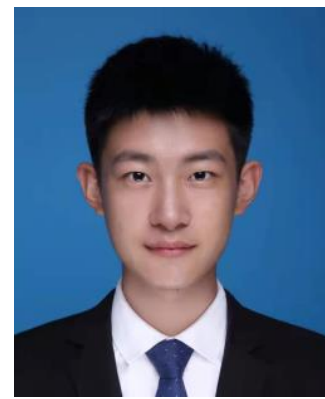

Xu Hou received a master's degree in electrical engineering from Chongqing University in 2019. Now he works in Ningbo Power Supply Company of State Grid. The main research direction is new power electronic devices. 